\title{
Smad transcription factors
}

\author{
Joan Massagué, ${ }^{1,4}$ Joan Seoane, ${ }^{2}$ and David Wotton ${ }^{3}$ \\ ${ }^{1}$ Cancer Biology and Genetics Program, Howard Hughes Medical Institute, Memorial Sloan-Kettering Cancer Center, New \\ York, New York 10021, USA; ${ }^{2}$ ICREA, Medical Oncology Research Program, Vall d'Hebron University Hospital Research \\ Institute, 08035 Barcelona, Spain; ${ }^{3}$ Department of Biochemistry and Molecular Genetics, and Center for Cell Signaling, \\ University of Virginia, Charlottesville, Virginia 22908, USA
}

Smad transcription factors lie at the core of one of the most versatile cytokine signaling pathways in metazoan biology-the transforming growth factor- $\beta$ (TGF $\beta$ ) pathway. Recent progress has shed light into the processes of Smad activation and deactivation, nucleocytoplasmic dynamics, and assembly of transcriptional complexes. A rich repertoire of regulatory devices exerts control over each step of the Smad pathway. This knowledge is enabling work on more complex questions about the organization, integration, and modulation of Smad-dependent transcriptional programs. We are beginning to uncover self-enabled gene response cascades, graded Smad response mechanisms, and Smad-dependent synexpression groups. Our growing understanding of TGF $\beta$ signaling through the Smad pathway provides general principles for how animal cells translate complex inputs into concrete behavior.

As evolution unfolded and multicellular life forms emerged, so did the need for tight control over the ability of individual cells to move, divide, differentiate, and organize. Intricate intercellular communication systems evolved to ensure the proper behavior of individual cells in the context of the whole organism. Among these forms of communication, one of the most prevalent involves secretory polypeptides that are recognized by membrane receptors coupled to transcriptional regulatory factors. With its 42 members in the human genome, seven in Drosophila, and four in Caenorhabditis elegans, the transforming growth factor- $\beta$ (TGF $\beta$ ) family is one of the most prominent representatives of this class of molecules. TGF $\beta$ and its family members-the nodals, activins, bone morphogenetic proteins (BMPs), myostatins, anti-Muellerian hormone (AMH), and others-exert profound effects on cell division, differentiation, migration, adhesion, organization, and death. These factors may be produced by many cell types, as in the case of TGF $\beta$, or very few, as in the case of myostatin, and they may be active from the earliest stages of

[Keywords: Smad; TGF- $\beta$; signaling; transcription] ${ }^{4}$ Corresponding author.

E-MAIL massaguj@mskcc.org; FAX (212) 717-3298.

Article and publication are at http://www.genesdev.org/cgi/doi/10.1101/ gad. 1350705 embryo development through adulthood, as in the case of the BMPs, or for very limited periods during development, as in the case of AMH. On the whole, the TGF $\beta$ family provides a paradigm of functional versatility among hormonally active polypeptides.

The quest to understand how cells read these signals started as soon as these factors were isolated in the early 1980s and has continued unabated ever since. By now, we have obtained a fairly robust understanding of the biochemical backbone of the TGF $\beta$ signaling pathway, and a growing sense for how cells translate these signals into responses. At the core of this pathway lie the Smad transcription factors. TGF $\beta$ induces its membrane receptors to directly activate Smad proteins that then form transcriptional complexes to control target genes (Fig. 1). What is not so simple is how these complexes activate or repress hundreds of target genes at the same time, in the same cell, and under tightly controlled conditions. This complexity has been the subject of much research in recent years and is the focus of the present review. For more information on the biology of the TGF $\beta$ family, we would recommend several classical reviews (Letterio and Roberts 1998; Whitman 1998; Massagué and Chen 2000; Massagué et al. 2000; Derynck et al. 2001; Attisano and Wrana 2002; Schier 2003). Other recent reviews (Derynck and Zhang 2003; Siegel and Massagué 2003) and research articles (Foletta et al. 2003; Ozdamar et al. 2005) cover the emerging topic of Smad-independent pathways in TGF $\beta$ signaling.

\section{Basic features of the Smad proteins}

Eight Smad proteins are encoded in the human and mouse genomes, four in Drosophila, and three in C. elegans (Massagué 1998). Only five of the mammalian Smads-Smad1, Smad2, Smad3, Smad5, and Smad8_-act as substrates for the TGF $\beta$ family of receptors; these are commonly referred to as receptor-regulated Smads, or RSmads (Fig. 2A). Smads 1, 5, and 8 serve principally as substrates for the BMP and anti-Muellerian receptors, and Smads 2 and 3 for the TGF $\beta$, activin, and Nodal receptors. Smad4, also referred to as Co-Smad, serves as a common partner for all RSmads (Fig. 2B). Smad6 and Smad7 are inhibitory Smads that serve as decoys interfering with Smad-receptor or Smad-Smad interactions. 
Figure 1. Functional and structural features of the TGF $\beta-S m a d$ pathway. TGF $\beta$ family members are dimeric ligands that remain in latent form by binding to their propeptide, or in trapped form by binding to occluding factors. On release from these inactive states, the ligand binds to pairs of membrane receptor serine/threonine kinases (receptor types I and II), promoting the formation of a hetero-tetrameric receptor complex. The cytoplasmic region of the type I receptor contains a canonical protein kinase domain (purple) preceded by a regulatory region or GS domain (green) to which the inhibitor FKBP12 (red) binds to enforce the inactive basal state. Phosphorylation of the GS domain by the type II receptor creates a repeated $\mathrm{pS}-\mathrm{x}-\mathrm{pS}$ motif that serves as a docking site for receptor-regulated Smad proteins (RSmad). In the basal state, RSmads and Smad4 undergo a constant nucleocytoplasmic shuttling. Anchor proteins capture RSmads for presentation to the activated type I receptor. Receptor-mediated phosphorylation at the $\mathrm{C}$ terminus of RSmads creates a $\mathrm{pS}-\mathrm{x}-$

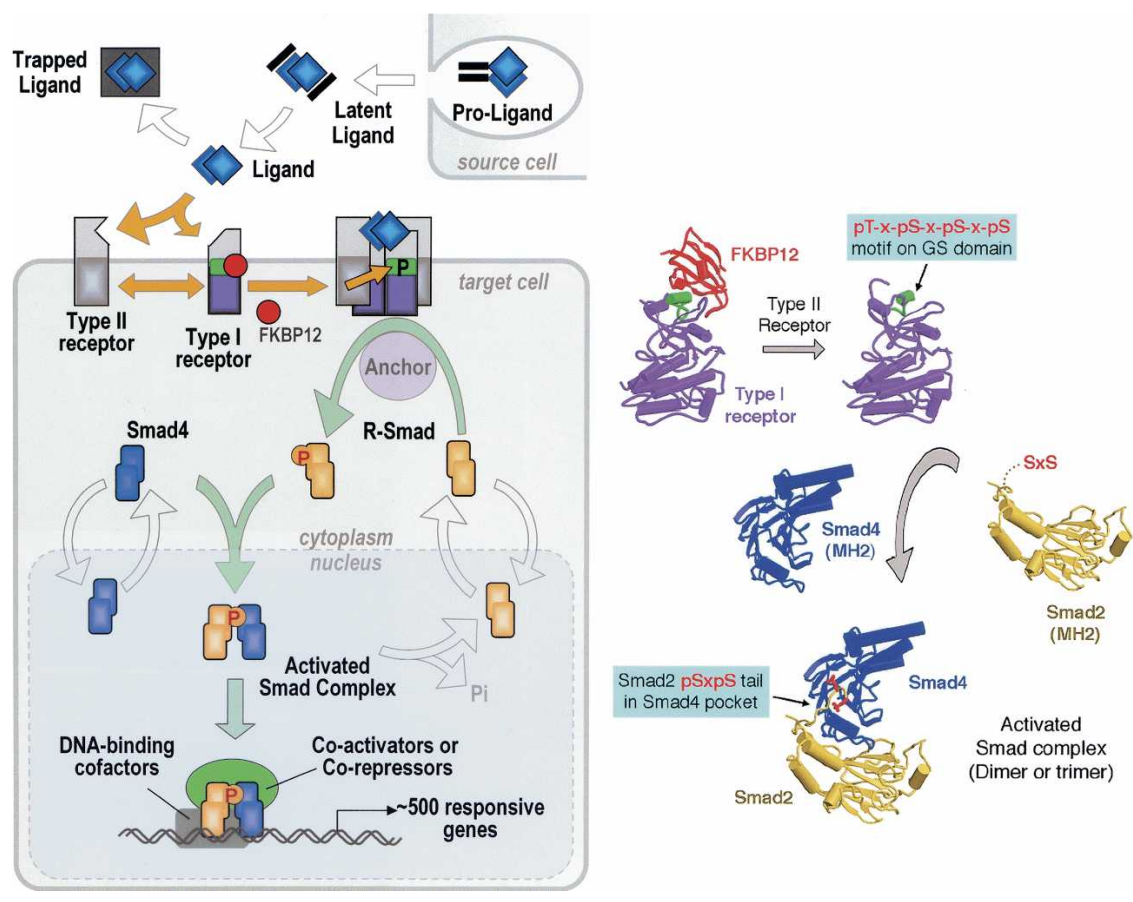
pS motif (red P), allowing the accumulation of RSmad in the nucleus and the recognition of this motif by a basic pocket in Smad4. The resulting Smad complex incorporates different DNA-binding cofactors that confer target gene selectivity and influence the recruitment of either transcriptional coactivators or corepressors. Several hundred genes are regulated by TGF $\beta$ in this fashion, of which two-thirds are activated by the signal and the rest are repressed. RSmad dephosphorylation terminates the signaling cycle. (Crystal structures adapted from Shi et al. 1997; Huse et al. 1999, 2001; Wu et al. 2000, 2001b).

The Mad protein in Drosophila, which was the first identified member of this family (Raftery and Sutherland 1999), is the ortholog of mammalian Smad1/5, whereas dSmad2, Medea, and Dad are the orthologs of Smad2/3, Smad4, and Smad6/7, respectively. The Smad family in C. elegans includes Sma1, Sma2, and Sma3 (Das et al. 1999). The name "Smad" was coined with the identification of human Smadl in reference to its sequence similarity to the Sma and Mad proteins (Liu et al. 1996).

Smad proteins are $\sim 500$ amino acids in length and consist of two globular domains coupled by a linker region (Fig. 2A; Shi and Massagué 2003). The N-terminal domain, or "Mad-homology 1" (MH1) domain, is highly conserved in all RSmads and Smad4 but not in Smads 6 and 7. The linker region is quite divergent between the various subgroups, whereas the C-terminal or $\mathrm{MH} 2$ domain is conserved in all Smad proteins. Functional studies, together with the X-ray crystal structure analysis of the $\mathrm{MH} 1$ and $\mathrm{MH} 2$ domains, have provided critical insights into the principal interactions of Smad proteins with other proteins and with DNA. The MH1 domain is a DNA-binding module stabilized by a tightly bound zinc atom. The contact with DNA is primarily established by a $\beta$-hairpin structure, which is conserved in all the RSmads and Smad4. Interestingly, the most abundant splice form of Smad2 contains an insert (encoded by exon 3) that blocks DNA binding. The MH1 domain is followed by the linker region, a flexible segment with binding sites for Smurf (Smad ubiquitination-related factor) ubiquitin ligases, phosphorylation sites for several classes of protein kinases, and, in Smad4, a nuclear export signal (NES).

The Smad MH2 domain is highly conserved and is one of the most versatile protein-interacting modules in signal transduction. RSmads have a conserved C-terminal motif, Ser-X-Ser, that is phosphorylated by the activated receptor. A pocket lined with basic residues interacts with the phosphorylated region of the activated receptor in the case of RSmads and with the phosphorylated tail of RSmads in the case of Smad4. A set of contiguous hydrophobic patches, referred to as the "hydrophobic corridor", on the surface of the MH2 domain mediates interactions with cytoplasmic retention proteins, with components of the nuclear pore complex (nucleoporins), and with DNA-binding cofactors. A region overlapping the linker and MH2 regions ("Smad4 activation domain", SAD) mediates interactions with transcriptional activators and repressors (Fig. 2A).

\section{Smad activation and deactivation}

The striking ability of Smad proteins to accumulate in the nucleus in response to TGF $\beta$ or BMP was one of the early key observations placing Smads downstream of the TGF $\beta$ receptors (Hoodless et al. 1996; Liu et al. 1996). Smad proteins undergo a constant process of nucleocytoplasmic shuttling, and their nuclear accumulation results from receptor-mediated phosphorylation events that decrease the affinity of RSmads for cytoplasmic anchors and increase their affinity for nuclear factors (Shi 

Smad1, Smad2,
A


Smad3, Smad5, Smad8


B

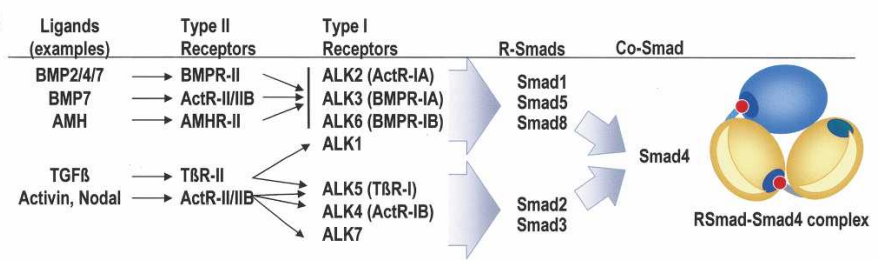

I-Smad Smad6 Smad7 actions (see Fig. 3). (B) Some examples of mammalian TGF 3 family members and their relationships with the five type II receptors, the seven type I receptors, the five RSmads, and the single Co-Smad. The schematic depicts a hetero-trimeric Smad complex consisting of two RSmad molecules and one Smad4 (only the MH2 domains are shown). RSmad-Smad4 heterodimers have also been described.

Figure 2. Smad proteins and their structural elements. (A) Smad proteins consist of two conserved globular domains-the MH1 and MH2 domains-and a variable linker region. The seven mammalian Smad proteins are listed under their corresponding classes. In RSmads and Smad4, the MH1 domain contains a $\beta$-hairpin structure for binding to DNA. I-Smads lack MH1 domain. The linker region of RSmads contains multiple phosphorylation sites for MAPKs, CDKs, and other protein kinases. In RSmads and I-Smads, the linker region contains a PY motif for recognition by the WW domains in Smurf ubiquitin ligases. The linker region of Smad4 contains an NES. The MH2 domain contains a basic pocket for interaction with activated type I receptors in the case of the RSmads, and in both the RSmads and Smad4 for interaction with the pS-x-pS motif /red ball) of RSmads. On the surface of the $\mathrm{MH} 2$ domain in RSmads, a contiguous set of hydrophobic patches or hydrophobic corridor serves as a site for multiple interand Massagué 2003; Xu and Massagué 2004). Subsequent dephosphorylation of RSmads causes their return to the cytoplasm for another round of receptor-mediated phosphorylation and nuclear translocation (Inman et al. 2002). This ensures a constant sensing of the receptor activation state by the Smad pathway.

\section{Smad nucleocytoplasmic dynamics}

The mechanisms of Smad nuclear import and export have been extensively studied over the last few years, particularly in Smads 2, 3, and 4. Interestingly, the nuclear import of these proteins can occur without the intervention of nuclear transport factors (Xu et al. 2000, 2002). Many proteins undergoing nuclear translocation in response to regulatory signals rely on importins, a set of factors that mediate nuclear import by recognizing a motif called the nuclear localization signal (NLS) in the cargo proteins (Jans et al. 2000). The classic NLS motif consists of a cluster of basic residues and is recognized by importin- $\alpha$. Importin- $\alpha$ binds to importin- $\beta$, which directly interacts with the nuclear pore components-nucleoporins-to negotiate the passage of the importin- $\beta$ importin- $\alpha$-cargo complex into the nucleus (Mattaj and Englmeier 1998; Gorlich and Kutay 1999). However, the nuclear translocation of Smad proteins can occur independently of importins because Smad proteins can directly interact with nucleoporins (Xu et al. 2000, 2002). This interaction maps to the hydrophobic corridor in the Smad MH2 domain and to the FG repeat region on the nucleoporins Nup153 and Nup214 (Fig. 3; Xu et al. 2002). The FG repeat region is also the region for nucleoporin interaction with importins (Bayliss et al. 2000). Importin-independent transport has also been described for other signaling factors, including $\beta$-catenin in the Wnt signaling pathway (Yokoya et al. 1999) and ERK2 MAP kinase in response to Ras-mediated mitogenic signals (Whitehurst et al. 2002).
Some Smad proteins may additionally undergo nuclear import via importins. A conserved lysine-rich sequence in the MH1 domain of Smads that resembles classical NLS motifs was hypothesized, and shown, to interact with importins (Xiao et al. 2000; Kurisaki et al. 2001). This conserved lysine-rich sequence forms an $\alpha$-helix right next to the DNA-binding motif in the MH1 domain, not an extended loop as would be structurally required for recognition by importin- $\alpha$ (Shi et al. 1998; Chai et al. 2003). Indeed, Smad3 interacts with importin- $\beta$, not importin- $\alpha$ (Xiao et al. 2000; Kurisaki et al. 2001). Importin binding has been detected with overexpressed Smad3 and Smad4 but not Smad2. This inability of Smad2 has been attributed to the presence of the exon 3-encoded insert in the MH1 domain. One study comparing the efficiency of $\operatorname{Smad} 3$ translocation by the importin-dependent and -independent mechanism indicated that the importin-dependent process is considerably weaker (Xu et al. 2003). On balance, it appears that Smads 2, 3, and 4 undergo nuclear import by means of direct interactions with nucleoporins, and this process may be aided by importin- $\beta$ in the case of Smads 3 and 4.

The intrinsic asymmetry of the nuclear pore complex, and the distribution of different nucleoporins along the span of the pore, are thought to allow proteins docking on one side of the pore to move unidirectionally to the other side and vice versa (Rout et al. 2000). Indeed, the direct interaction of Smads 2 and 3 with nucleoporins has been shown to enable nuclear export as well as import (Xu et al. 2002). The presence of an NES and the recognition of this sequence by the general nuclear export factor CRM1, which are necessary for nuclear export of other proteins (Fornerod et al. 1997), are not required for the export of Smads 2 and 3. Interestingly, these properties are also shared by $\beta$-catenin (Yokoya et al. 1999), ERK2 (Whitehurst et al. 2002) and importin- $\beta$ (Fahrenkrog and Aebi 2003). 


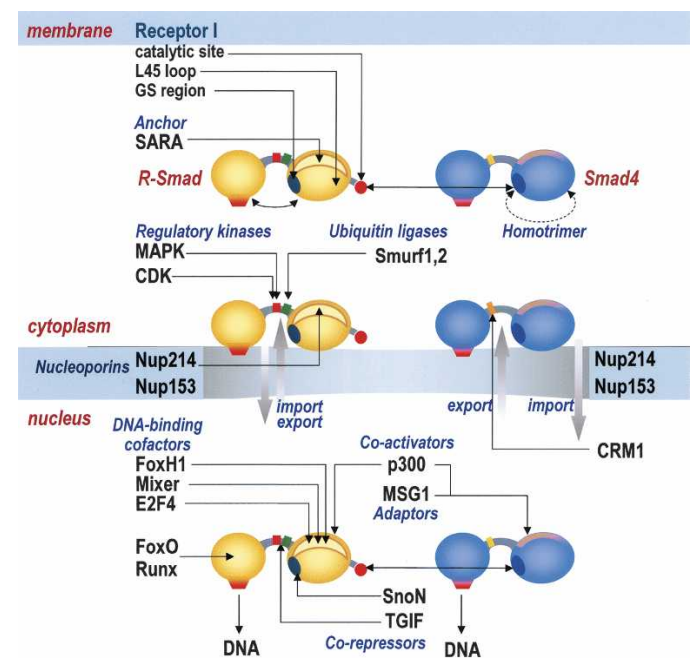

Figure 3. Smad interaction sites. Summary of representative interactions of RSmads and Smad4 with other proteins in the cytoplasm, nuclear pore, and nucleus. On a type I receptor kinase domain, the L45 loop specifies the receptor-RSmad interaction, the phosphorylated GS domain enables this interaction, and the catalytic domain phosphorylates the RSmad tail. On RSmad, the L3 loop (not shown) and the basic pocket (blue oval) match the receptor L45 loop and the GS domain. In the basal state, the MH1 and MH2 domains may interact in cis, and the MH2 domains of Smad4 in trans (dashed arrow), forming homotrimers. The phosphorylated tail of RSmads (red dot) is recognized by the basic pocket in Smad4. SARA, acting as a cytoplasmic anchor, and the nucleoporins Nup214 and Nup153, acting as mediators of nuclear import and export, interact with the hydrophobic corridor of RSmads. Smad4 import involved direct contacts with these nucleoporins, whereas export involves binding of CRM1 to the NES motif (orange mark) on the linker region of Smad4. In the cytoplasm or the nucleus, the linker region of RSmads is recognized by MAPKs, CDKs, and other kinases for phosphorylation and by Smurf ubiquitin ligases for polyubiquinitation. In the nucleus, different DNA-binding cofactors bind to RSmads in the hydrophobic corridor and others bind to the MH1 domain. Transcriptional coactivators such as p300 bind to the MH2 domain, in some cases with the assistance of adaptors such as MSG1. Corepressors may bind in competition with p300 (case of TGIF) or in competition with Smad4 (case of SnoN).

In the basal state, Smad4 is distributed throughout the cell and may also undergo a continuous shuttling between the cytoplasm and the nucleus (Fig. 3; Pierreux et al. 2000; Watanabe et al. 2000; Inman et al. 2002). Receptor-mediated phosphorylation at the C-terminal region of RSmad proteins creates a binding site for Smad4 (Wu et al. 2001b; Chacko et al. 2004). In principle, receptor-phosphorylated RSmads could associate with Smad4 in the cytoplasm and enter the nucleus as a RSmadSmad4 complex, or this complex could form after RSmads enter the nucleus. The site of Smad complex formation in the cell has not been systematically investigated, and it may depend on the cell type and conditions. Regardless, Smad4 is concentrated in the nucleus as a result of this interaction.

Unlike the nuclear export of Smads 2 and 3, the export of Smad4 is dependent on, or at least enhanced by, CRM1. Smad4 contains a leucine-rich NES in the linker region that is recognized by CRM1 (Figs. 2A, 3; Pierreux et al. 2000). The CRM1 inhibitor leptomycin B blocks the nuclear export of Smad4 without interfering with nuclear export of Smads 2 or 3 (Inman et al. 2002; Xu et al. 2002). The interaction with receptor-phosphorylated Smads 2 and 3 is thought to mask the NES in Smad4, protecting the RSmad-Smad4 complexes from recognition by CRM1 and nuclear export (Watanabe et al. 2000; Inman et al. 2002). When RSmads are dephosphorylated and the complex dissociates, the Smad4 NES becomes exposed again and nuclear export of Smad4 by CRM1 can proceed. Little is known about other inputs that may regulate the exposure of the Smad4 NES. However, an alternatively spliced mammalian Smad4 isoform (Pierreux et al. 2000) and a separate gene product, $\operatorname{Smad} 4 \beta$, in Xenopus (Watanabe et al. 2000) lack the NES and are constitutively located in the nucleus.

\section{Smad subcellular retention mechanisms}

Despite the intrinsic ability of RSmads to shuttle in and out the nucleus, many immunocytochemical studies have shown that in the basal steady state, RSmads are predominantly concentrated in the cytoplasm (Pierreux et al. 2000; Watanabe et al. 2000; Xu et al. 2002). This is thought to result from the action of cytoplasmic Smadbinding factors. Indeed, endogenous Smad proteins in the basal state are found in high-molecular mass oligomeric complexes, as determined by molecular-sizing chromatography (Jayaraman and Massagué 2000).

Different cytosolic proteins may function as Smad anchors and adaptors. The best characterized of the cytosolic retention factors for Smad2 and Smad 3 is the protein SARA (smad anchor for receptor activation) (Tsukazaki et al. 1998). SARA is a multidomain protein that contains an 80-amino-acid Smad-binding domain (SBD) and a FYVE phosholipid-binding domain that avidly binds to phosphatidyl inositol 3' phosphate on endosomal membranes. FYVE targets SARA preferentially to early endosomes (Di Guglielmo et al. 2003). As revealed by the X-ray crystal structure of the Smad2-SBD complex, the SBD of SARA makes contact with the three consecutive hydrophobic patches on the MH2 domain surface that constitute the hydrophobic corridor (Figs. 2, 3; Wu et al. 2000). This region is also involved in the interaction with the FG-repeat-containing domain nucleoporins and the binding of DNA-binding cofactors (Wu et al. 2000; Randall et al. 2002). Therefore, the interaction with SARA is incompatible with translocation of $S m a d 2 / 3$ into the nucleus and formation of transcriptional complexes.

Receptor-mediated phosphorylation causes a decrease in the affinity of Smad2 for SARA (Wu et al. 2001b). This occurs without a concomitant increase in Smad affinity for nucleoporins. In vivo, however, this drop in affinity for SARA is sufficient for Smad2/3 dissociation and movement into the nucleus, where $S m a d 2 / 3$ are retained by interactions with Smad4 and additional proteins, as 
well as with the DNA. Dephosphorylation and dissociation of Smad transcriptional complexes are thought to end this retention, allowing the export of RSmad out of the nucleus (Inman et al. 2002).

The hydrophobic corridor and adjacent regions are involved in binding contacts not only with SARA and nucleoporins, but also with DNA-binding partners in the nucleus (Fig. 3; Randall et al. 2002). Two such partners of Smad2/3, the forkhead family member FoxH1 and the homeodomain transcription factor Mixer, share a conserved Smad-interacting motif (SIM) that has sequence similarity with the SBD of SARA (Germain et al. 2000; Wu et al. 2000). Interestingly, the SIM is shorter than the SBD and, contrary to the SBD, it binds to Smad without occluding the Smad-Smad interface (Wu et al. 2001b). Thus SIM-containing factors can bind to Smad2/3Smad4 oligomers, whereas SARA SBD interacts with monomeric Smad2/3.

As the same Smad protein surface interacts with cytoplasmic retention factors, nuclear pore components, and nuclear-interacting factors, this surface creates mutually exclusive interactions-and hence, competitionbetween Smad-binding components (Fig. 3). A soluble SBD peptide has been used as an effective inhibitor of Smad2/3 nuclear translocation (Xu et al. 2000, 2003). Nup214 and Nup153 compete with SARA for Smad2 in binding assays (Xu et al. 2002). Overexpression of FoxH1 causes the concentration of Smad2/3 in the nucleus even in the absence of TGF $\beta$, providing evidence for the constant nucleocytoplasmic traffic of Smads (Xu et al. 2002). This FoxH1-Smad2/3 interaction is transcriptionally inert because, without receptor mediated phosphorylation, Smad2/3 in this complex cannot recruit Smad4.

\section{Smad adaptors for receptor interaction}

Several adaptor proteins that facilitate the Smad-receptor interaction have been described, of which SARA is the most extensively characterized. By regionally restricting Smad2/3 proteins to the plasma membrane and early endosomes, SARA facilitates the interaction of Smads 2 and 3 with the activated TGF $\beta$ receptor (Tsukazaki et al. 1998). The activated receptor complex is internalized via clathrin-coated pits from the plasma membrane to the early endosomes, where SARA-bound Smads are thought to be most readily accessible (Di Guglielmo et al. 2003). However, this interaction also appears to occur at the plasma membrane prior to receptor internalization (Di Guglielmo et al. 2003). Another FYVE domain protein, Hgs, has been found to cooperate with SARA on Smad phosphorylation (Miura et al. 2000). Activated TGF $\beta$ receptor complexes are also internalized via lipid rafts and caveolae, but this route is thought to lead to receptor interaction with the E3 ubiquitin ligase Smurf2 that targets the receptor for inactivation (Di Guglielmo et al. 2003). However, genetic evidence for the necessity for SARA in Smad2/3 signaling is lacking, and so it remains to be established whether SARA is in fact a major player in this pathway.

Other proteins that have been proposed to participate in the interaction of Smad2/3 with the TGF $\beta$ receptor, including Disabled-2 (Hocevar et al. 2001), Dok-1 (Yamakawa et al. 2002), Axin (Furuhashi et al. 2001), the ELF $\beta$-spectrin (Tang et al. 2003), and a cytoplasmic isoform (cPML) of the promyelocytic leukemia protein (Lin et al. 2004), are interesting members of this group. cPML has been proposed to interact with SARA, Smad2/3, and the TGF $\beta$ receptor and to be critical for TGF $\beta$ phosphorylation of Smad2/3 and TGF $\beta$ signaling (Lin et al. 2004). However, PML-deficient mice develop fairly normally (Wang et al. 1998), whereas embryos deficient in TGF $\beta$ receptors or Smad2 do not (Oshima et al. 1996; Waldrip et al. 1998; Heyer et al. 1999). The proteins TRAP-1 (TGFß-receptor-associated protein) (Wurthner et al. 2001) and TLP (TRAP-1-like protein) (Felici et al. 2003) have been described as adaptor proteins that interact with the receptor complex and facilitate the formation of Smad2/3-Smad4 complexes. Many of these interactions require a more thorough examination before their significance as Smad adaptors can be established. Furthermore, little is known about factors that facilitate RSmad-receptor interactions in the BMP pathway. Smad1 does not interact with SARA, but given the overall similarity between these pathways, the existence of a SARA-like factor for Smads 1, 5, and 8 remains possible.

\section{Smad phosphorylation by TGFß receptor kinases}

Smad phosphorylation by the activated TGF $\beta$ receptor complex is a pivotal event in the initiation of TGF $\beta$ signal transduction. The mechanism of TGF $\beta$ receptor activation was established by combining biochemical and genetic approaches (Wrana et al. 1994). This process and its structural basis have been reviewed in detail elsewhere (Shi and Massagué 2003). Briefly, TGF $\beta$ binds to pairs of receptor serine/threonine kinases, known as the TGF $\beta$ type I (T $\beta R$-I) and type II (T $\beta R$-II) receptors, forming a hetero-tetrameric receptor complex. In this complex, T $\beta$ R-II phosphorylates a serine/threonine-rich region, called the GS region, that is located $\mathrm{N}$-terminal to the canonical kinase domain of T $\beta$ R-I (Fig. 1). In the absence of ligand, the small proteins FKBP12 and FKBP12.6 bind to the GS region and occlude the phosphorylation sites in this region (Y.G. Chen et al. 1997; Datta et al. 1998). The X-ray crystal structure of the FKBP12-TßR-I cytoplasmic domain complex revealed that the bound FKBP12 additionally enforces a catalytically inactive conformation of the T $\beta$ R-I kinase domain by pressing against the active center and causing a misalignment of the critical catalytic amino acid residues (Huse et al. 1999). Thus, in the basal state, the GS region acts as a docking site for FKBP12 and an auto-inhibitory element of the receptor kinase (Fig. 1).

T $\beta$ R-II appears to be a constitutively active kinase (Wrana et al. 1994). Ligand access to the receptors is a tightly regulated process, with numerous proteins acting as ligand traps that bind various members of the TGF $\beta$ family and prevent their contact with cell surface receptors (Fig. 1; for reviews, see Massagué and Chen 2000; Shi and Massagué 2003). In the ligand-induced receptor com- 
plex, T $\beta$ R-II gains access to the GS region of T $\beta$ R-I, catalyzing the phosphorylation of alternating serine (or threonine) residues in the sequence Thr-Thr-Ser-GlySer-Gly-Ser (Wrana et al. 1994; Massagué 1998). This interaction is negatively regulated by the pseudoreceptor BAMBI, which intercalates in the receptor complex /Onichtchouk et al. 1999). Phosphorylation of T $\beta R-I$ turns the GS region from a FKBP12-binding site to a binding site for Smad2/3 (Huse et al. 2001), providing a case of remarkable economy of function within a kinase structural element. Smad2/3 are then phosphorylated by T $\beta$ R-I and released to propagate the signal.

This general mechanism applies to all TGF $\beta$ and BMP family receptors characterized to date, from human through Drosophila (Shi and Massagué 2003). The RSmad substrate specificity of a given receptor complex is determined by a particular region, the L45 loop, in the kinase domain of the type I receptor and a complementary region, the L3 loop, on the $\mathrm{MH} 2$ domain of RSmads (Fig. 3). T $\beta$ R-I (also known as ALK5) and the nodal/activin type I receptors ALK2 and ALK 7 recognize Smads 2 and 3, whereas ALK1, ALK3, and ALK6 recognize Smads 1,5 , and 8 . Thus, the phosphorylated GS region drives receptor interaction with RSmads, whereas the L45 loop determines the specificity of this interaction.

Receptor-mediated phosphorylation occurs at two serine residues in the extreme C-terminal sequence SerVal-Ser (Ser-Met-Ser in Smad2) of RSmads. pSer-X-pSer is the paradigmatic activation motif of the TGF- $\beta / \mathrm{Smad}$ pathway (Fig. 1). This motif occurs both in the GS region of type I receptors upon phosphorylation by type II receptors and in the C-terminal tail of RSmads upon phosphorylation by type I receptors. Together with the Cterminal carboxyl group, this di-phosphoserine moiety constitutes an acidic tail that binds to a basic pocket in the Smad4 MH2 domain (Fig. 1; Wu et al. 2001b; Chacko et al. 2004). As a result, RSmad-Smad4 oligomers are formed that nucleate a large number of transcriptional regulatory complexes.

In solution, the unphosphorylated Smad2 MH2 domain is a monomer but the phosphorylated form is a homotrimer (Wu et al. 2001b), and Smad4 also forms homotrimers (Shi et al. 1997). Smad2/3 mixed oligomers (presumably trimers) have been observed in cells on TGF- $\beta$ stimulation (Wu et al. 2001b; Chacko et al. 2004), but their function is unknown. More significant from the standpoint of signal transduction are the RSmadSmad4 oligomers, both heterodimers (RSmad-Smad4) or heterotrimers (two RSmads molecules plus one Smad4 molecule) (Figs. 1, 2B). As revealed by X-ray crystallographic studies, these oligomers are stabilized by interactions within an extensive protein-protein interface between $\mathrm{MH} 2$ domains plus the binding of the pSer-X-pSer motif of one $\mathrm{MH} 2$ domain into the di-phosphoserinebinding pocket on the adjacent $\mathrm{MH} 2$ domain (Wu et al. 2001b). Mutation of these serine residues into aspartic acid mimics this interaction. Several Smad-inactivating mutations found in tumors map to the MH2 domain interface and inhibit Smad oligomer formation (Wu et al. 2001b).

\section{Smad dephosphorylation}

A steady level of Smad2/3 phosphorylation is achieved in cells within 15-30 min of exposure to of TGF $\beta$ addition and can last for several hours. Eventually, a drop in TGF $\beta$ levels in the extracellular space, receptor inactivation by internalization and degradation, or the action of negative feedback mechanisms leads to a loss of Smad phosphorylation.

Recent evidence suggests that sustained receptor activity is required for the maintenance of the steady-state phospho-Smad levels over the duration of the TGF $\beta$ stimulation. The existence of a rapid cycle of dephosphorylation and return to the cytoplasm has been inferred from results using a TGF $\beta$ receptor kinase inhibitor (Inman et al. 2002). Interrupting signaling by addition of this inhibitor causes a precipitous loss of phosphoSmad2, with a half-life of $<30$ min (Inman et al. 2002). This loss is primarily caused by dephosphorylation (Fig. 1; Inman et al. 2002), although ubiquitination and proteasome-mediated degradation of Smad2 in the nucleus may also eventually occur (Lo and Massagué 1999). RSmad dephosphorylation seems to occur in the nucleus, as suggested by the underphosphorylated state of Smad2 protein exported from the nuclei of permeabilized TGF $\beta$-treated cells (Xu et al. 2002). Dephosphorylation is accompanied with dissociation of the RSmadSmad4 complex and export of its components to the cytoplasm. Thus, RSmads undergo repeated cycles of receptor-mediated phosphorylation and re-entry into the nucleus, as long as TGF $\beta$ receptors remain active (Fig. 1). Smad signaling activity becomes thereby tied to receptor activation. The identity of the RSmad phosphatase(s) has not been revealed, but their identification will be of great interest because the action of this enzyme(s) causes the termination of Smad signal transduction.

\section{Smad transcriptional complexes}

The RSmad-Smad4 complex formed upon receptor-mediated phosphorylation of RSmad acts as the core of many different multiprotein assemblies that target different genes for either activation or repression. The Smad proteins in this complex, via their $\mathrm{MH} 1$ domain, can bind to DNA. Almost universally, however, Smads must interact with other DNA-binding cofactors to achieve high affinity and selectivity for specific subsets of target genes. Understanding how the $\mathrm{MH} 1$ domain recognizes DNA and how a RSmad-Smad4 complex engages different DNA-binding partners is essential for delineating Smad transcriptional programs.

\section{DNA-binding determinants in the MH1 domain:} $\beta$-hairpin and exon 3 insert

Smad4 and all RSmads (except the long form of Smad2, see below) can directly bind to DNA. The X-ray crystal structure of the Smad3 MH1 domain bound to the SBE shows that a $\beta$-hairpin (i.e., two anti-parallel short $\beta$-strands separated by a linker loop) in the MH1 domain 
mediates this binding interaction. The $\beta$-hairpin is inserted in the major groove of the DNA and establishes hydrogen bonds with nucleotides in three base pairs of the Smad-binding element (Shi et al. 1998). The $\beta$-hairpin sequence is conserved in all RSmads and Smad4 (Shi et al. 1998), arguing that this Smad-DNA contact cannot provide much selectivity in the interaction of different Smads with their corresponding target genes.

Interestingly, the most abundant splice variant of Smad2 in vertebrates contains an insert in the MH1 domain, in the vicinity of the $\beta$-hairpin, that prevents Smad2 binding to DNA (Shi et al. 1998). This insert is codified by exon 3 of Smad2. The predicted sequence of the Smad2 ortholog in Drosophila, dSmad2, also contains an insert in this position (Brummel et al. 1999). A splice variant of Smad2 lacking the exon 3 insert is able to bind DNA (Yagi et al. 1999). Because the splice form containing the insert is the most abundant and was cloned first, this variant is called Smad2, whereas the version lacking the insert, and thus most closely resembling the other RSmads, is stuck with the name Smad2 $2 \mathrm{E} 3$.

The endogenous Smad2 and Smad2 $\Delta \mathrm{E} 3$ proteins are coexpressed in various cell types at a ratio ranging from 3:1 to 10:1 (Dunn et al. 2005). Smad2-null mice show an early embryonic lethal phenotype because Smad2 plays an essential role in patterning the embryonic axis and specifying the endoderm (Waldrip et al. 1998; Heyer et al. 1999|. Mice engineered to exclusively express Smad2 $\Delta$ E3 from the Smad2 locus are viable and fertile, indicating that full-length Smad2 with the insert is not required for viability (Dunn et al. 2005).

The role of the insert and its inhibitory effect on DNA binding remain a mystery. Smad2 might act as a competitive inhibitor of Smad2 $\Delta \mathrm{E} 3$ and Smad3 in transcriptional complexes. However, this scenario has not been borne out by the evidence. Smad2 was originally identified for its ability to act as a mediator and not an inhibitor of activin/TGF $\beta$-like transcriptional responses. Smad2 can associate with Smad4 and an additional DNA-binding cofactor to form transcriptional complexes. This was shown by the ability of the complex FoxH1-Smad2-Smad4 to mediate activation of the Mix2 promoter (X. Chen et al. 1997; Liu et al. 1997). Still, it is possible that Smad2 may act as an effector of some gene responses and as an inhibitor of others. Furthermore, the exon 3-encoded insert may have functions not related to transcriptional regulation. Of interest in this regard, Smad2 $\Delta E 3$, like Smad3, forms high-molecular mass oligomeric complexes in the basal state, whereas Smad2 is essentially monomeric under these conditions (Jayaraman and Massagué 2000).

\section{Smad-binding elements}

Using a bound-oligonucleotide selection strategy, the binding specificity of recombinant Smad proteins was originally defined as $5^{\prime}$-GTCTAGAC-3' (Zawel et al. 1998) and later shown to be $5^{\prime}$-GTCT-3', or its complement 5'-AGAC-3', called the Smad-binding element
(SBE). Many Smad-responsive promoter regions contain one or more SBEs, which in many instances contain an extra base, as 5'-CAGAC-3'. The crystal structure of the MH1-SBE complex shows that Smads recognize the 5'GTCT-3' sequence through the $\beta$-hairpin in the MH1 domain (Shi et al. 1998).

The affinity of Smad proteins for the SBE is too low to support binding of a Smad complex to a single SBE in vivo (Shi et al. 1998). Sufficient binding affinity for transcriptional activation can be artificially achieved with concatemers of multiple SBEs (Zawel et al. 1998). As activated Smad complexes consist of Smad oligomers, the presence of multiple SBEs likely enables tight binding through cooperative interactions between multiple MH1 domain-SBE contacts by the same Smad complex. However, natural Smad target promoters seldom contain SBE concatemers, and those that contain up to four SBEs still require cooperating factors for effective DNA binding (Seoane et al. 2004).

High-affinity binding of the Smad complex is thought to occur through the incorporation of a different DNAbinding cofactor into the RSmad-Smad4 complex (Fig. 1). This allows the recognition of promoter regions that present one SBE in the vicinity of the cognate sequence for that particular cofactor. This mode of interaction provides a basis for high affinity and selectivity in the recognition of target genes and a venue for the differential action of TGF $\beta$ in different cell types (Massagué and Wotton 2000). As discussed below, the interaction of Smads with other transcription factors to generate target gene-specific transcriptional complexes is crucial for the pleiotropic nature of TGF $\beta$ signaling. However, no crystal structure of a natural Smad complex bound to its cognate DNA region has been described to date, leaving us to wonder how such interactions may actually take place.

\section{SBE variants and GC-rich elements}

Some TGF $\beta$ responsive regions lack a canonical SBE but contain sequences that may function as such because of a certain degree of tolerance in the MH1-SBE interaction. Based on the crystal structure of this complex, the second nucleotide in the 5'-GTCT-3' sequence does not support interactions with the MH1 domain, thus allowing substitutions that do not impair Smad binding (Shi et al. 1998). Such "degenerate" SBEs have been proposed in the TGF $\beta$ inhibitory element (TIE) in the $c-M y c$ promoter (Chen et al. 2002). The TIE does not contain a canonical SBE but binds a Smad3-Smad4 complex, as verified by chromatin immunoprecipitation assays (Chen et al. 2002). Scrutiny of this region in vitro and in cells has demonstrated that the sequence 5'-GGCTT-3' is contacted by Smad3 or Smad4 (Chen et al. 2002; Frederick et al. 2004). Either way, the Smad-DNA interaction in the $c-M y c$ TIE is buttressed by E2F4/5 and DP1 as DNA-binding cofactors in the $c-M y c$ inhibitory complex (Chen et al. 2002; Frederick et al. 2004).

In certain promoters, Smad complexes recognize GCrich regions. Mad (Drosophila Smad1) and Medea (Dro- 
sophila Smad4) were shown to interact with a GCCGnCGC sequence in the promoters of Vestigial (Kim et al. 1997) and Tinman (Xu et al. 1998). Interestingly, the murine counterpart of Tinman, Nkx2.5, contains a canonical SBE that interacts with the Smad complex (Lien et al. 2002; Brown et al. 2004). The BMP-responsive element (BRE) in the promoter of Smad6 contains four overlapping copies of a GC-rich motif. Direct binding of Smads to GC-rich sequences has been demonstrated in oligonucleotide binding assays using extracts from cells that overexpress Smad5 and Smad4 (Ishida et al. 2000). Based on these observations, GC-rich motifs are sometimes referred to as "Smad1-binding elements". However, it would be erroneous to imply that Smad1/5/8 bind GC-rich motifs, whereas Smad2/3 bind to SBEs. The first Smad1-binding element defined in vertebrates, in the BMP-responsive region of the Xenopus Vent-2 promoter, is a canonical SBE (Hata et al. 2000). Furthermore, binding of Smad1-Smad4 complexes and Smad3-Smad4 complexes to the Id1 promoter requires both SBE and GC-rich elements. Both elements are required for BMPmediated induction of Id1 (Korchynskyi and ten Dijke 2002; Lopez-Rovira et al. 2002; Kang et al. 2003) and TGF $\beta$-mediated repression of $I d 1$, the difference being determined by the recruitment of an additional factor, ATF3 (Kang et al. 2003). No crystal structure of a Smad molecule bound to a GC region has been reported, but the dual interaction with SBE and GC-rich motifs invites the speculation that the MH1 domain might actually contain separate DNA-binding sites for these two different sequences.

\section{Core Smad complexes: dimers and trimers}

Transcriptionally active Smad complexes are mediated by RSmad-Smad4 oligomers. The stoichiometry of such oligomers has been the subject of debate. The analysis of complexes formed with Smads containing acidic residue substitutions for the $\mathrm{C}$-terminal serine residues suggested that they form heterotrimers of two phosphoRSmad molecules and one Smad4 molecule (Chacko et al. 2001; Qin et al. 2001). Moreover, phospho-Smad2 and Smad4 each in isolation form homotrimers in solution (Shi et al. 1997; Wu et al. 2001b). These results indicated that functional RSmad-Smad4 complexes are probably heterotrimers (Chacko et al. 2001). However, the crystal structure of isolated $\mathrm{MH} 2$ domains of phospho-Smad2 supported as well a heterodimer model between Smad4 and the RSmad (Wu et al. 2001a,b). Recently, the X-ray crystal structure analysis of the complexes formed by the MH2 domains of phospho-Smad2-Smad4 and phosphoSmad3-Smad4, digested with chymotrypsin, shows that both complexes are heterotrimers comprising two phosphorylated RSmad subunits and one Smad4 (Chacko et al. 2004).

Studies on endogenous Smad transcriptional complexes in vivo have suggested a more complex scenario. Both heterodimers and heterotrimers may be formed depending on the target gene and other factors present in the complex (Inman and Hill 2002). For example, the
Mix2 promoter may be targeted by a heterotrimer Smad2-Smad2-Smad4 bound to FoxH1, whereas a Smad3-Smad4 heterodimer and an as yet unknown cofactor may be involved in targeting the $\operatorname{JunB}$ promoter (Inman and Hill 2002). The physical interaction of the Smad cofactors with the RSmad-Smad4 complexes might facilitate the formation of a heterodimer or a heterotrimer.

The regulation of $c-M y c, I d 1, p 21 C i p 1$, and other genes by TGF $\beta$ involves Smad3 preferentially over Smad2. Smad3 has a higher affinity than Smad2 for the cofactors-E2F4/5, ATF3, and FoxO, respectively—that target Smads to these gene promoters (Chen et al. 2002; Kang et al. 2003; Seoane et al. 2004). The role of Smad2 $\Delta$ E3 in these complexes has not been characterized. Therefore, the choice between Smad heterodimers and heterotrimers might depend on several variables, including the balance between Smad2 and $\operatorname{Smad} 2 \Delta E 3$, the other DNAbinding partners present in the complex, and the number of SBEs present in the target promoter.

\section{Smad4 requirement}

Whether Smad4 is always required in Smad transcriptional complexes remains an important yet elusive question. All endogenous Smad complexes described to date have been shown to contain Smad4. All Smad target genes characterized by chromatin immunoprecipitation showed Smad4 binding along with RSmads. Nevertheless, Smad4-deficient tumor cells and fibroblasts from Smad4-deficient mice still display some gene responses to TGFß (Sirard et al. 1998; Wisotzkey et al. 1998; Subramanian et al. 2004). Certain pancreatic carcinoma cells that lack Smad4 contain high levels of phosphorylated RSmads and respond to TGF $\beta$ receptor signaling with increased motility (Subramanian et al. 2004). TGF $\beta$ receptors could signal some of these responses via MAP kinases, phosphatidyl inositol 3'-kinase, PP2A protein phosphatases, or Rho family members (for review, see Derynck and Zhang 2003; Siegel and Massagué 2003), or as a result of effects on tight junction membrane components (Ozdamar et al. 2005). However, TGF $\beta$ signaling via RSmads independently of Smad4 remains a possibility, as suggested by the more severe phenotype of mad mutants compared with medea mutants in Drosophila (Wisotzkey et al. 1998) and Smad2-/- mice compared with Smad4 ${ }^{-/}$mice (Sirard et al. 1998; Chu et al. 2004). Phospho-RSmads might yet be shown to interact with factors distinct from, and in competition with, Smad4.

\section{Target gene selection by association with DNA-binding partners}

Activated RSmad-Smad4 complexes achieve high affinity and selectivity for target gene promoters by associating with diverse DNA-binding factors (Fig. 4A,B). The DNA-binding activities of the various components in the resulting complex cooperatively generate a high-af- 
A. Primary Activation

Celf-Enabling Gene Responses

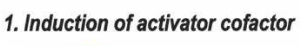

Mixer, OAZ
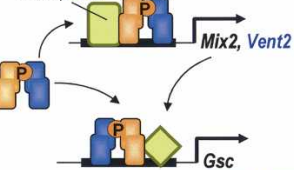

Bambi, smad7

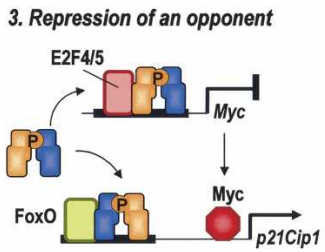

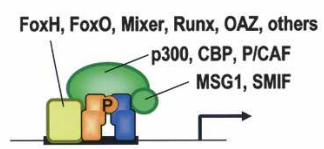

B. Primary Repression

E2F4/5, Nkx3.2, Runx2

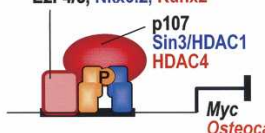

Osteocalcin

2. Induction of repressor cofactor

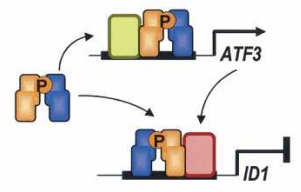

4. Repression and eviction of opponent

Schnurri

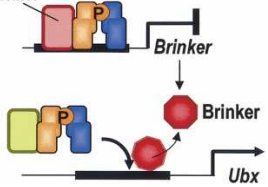

Figure 4. Models of transcriptional regulation by Smads. $(A)$ RSmad-Smad4 complexes, in combination with different DNAbinding cofactors, form assemblies that target specific genes. FoxH, FoxO, and Mixer are examples of DNA-binding cofactors for Smad2/3-Smad4, and OAZ for Smad1/5-Smad4. These complexes may recruit coactivators (e.g., p300, CBP, P/CAF) with the assistance of adaptor proteins (e.g., MSG1, SMIF). (B) RSmad-Smad4 complexes may also recruit corepressors as a function of the associated DNA-binding cofactor. Smad1Smad4 with Nkx3.2 recruits mSin3/HDAC1. Smad3-Smad4 with E2F4/5 recruits p107 and with Runx2 recruits HDAC4. The color coding indicates functionally linked components. $(C)$ In a growing number of cases, Smad-mediated transcriptional regulation appears to involve a self-enabling mechanism whereby Smads induces a gene response that then enables another Smad-dependent gene response. (1) In the Xenopus embryo, Mixer with Smad2-Smad4 induces expression of Mix2, which then mediates the induction of other genes with Smad2Smad4. Likewise, OAZ with Smad1-Smad4 induces expression of Vent2, which then apparently mediates the induction of other genes with Smad1-Smad4. (2) In human keratinocytes, Smad2/3-Smad4 with unknown cofactors induces expression of ATF3, which in complex with Smad3-Smad4 then mediates the repression of ID1. (3) By down-regulating the expression of $c$ MYC in epithelial cells, an E2F4/5-Smad3-Smad4 complex removes Myc-mediated repression from p21CIP1, thus enabling the activation of this gene by FoxO-Smad3-Smad4 complexes. (4) In the Drosophila embryo, repression of Brinker by a Schnurri-Mad-Medea complex facilitates the displacement of Brinker from the Ubx promoter by a competing Mad-Medea (with an unknown cofactor) complex.

finity binding interaction with target promoters that contain the cognate sequences. This interaction demands that the suitable DNA elements be present at the correct distance and orientation on the target promoter, so the interaction is highly selective. Among several hundred TGF $\beta$ target genes in a given cell, only a few may be targeted by a particular RSmad-Smad4-partner combination. A given cell type that does not express a particular Smad partner will be unable to mount the TGF $\beta$ gene response(s) that depend on that particular RSmad complex combination. This would make a gene response to TGF $\beta$ cell type dependent. Some DNA-binding partners can pair with $\operatorname{Smad} 2 / 3$ only and others with Smad1/5/8 only, thus establishing pathway specificity for TGF $\beta$ and BMP gene responses. Furthermore, in some cases Smad partners also determine the sign of the effectactivation or repression-that is exerted on a target gene. Smad partners therefore provide four levels of specificity: (1) target gene specificity, (2) pathway specificity, (3) cell type specificity, and (4) specific transcriptional effect.

Many Smad cofactors have been identified that fulfil this paradigm for different Smad target genes. Remarkably, these cofactors belong to different families of DNAbinding proteins, providing a basis for the breadth of TGF $\beta$ transcriptional responses. It should be noted that only a few of these interactions have been validated to date by analysis of endogenous (as opposed to overexpressed) proteins, chromatin immunoprecipitation analysis of protein binding to DNA in vivo, and genetic depletion of Smad partners. Whenever possible, we will focus here on examples that meet these stringent criteria.

The first identified Smad-interacting transcription factor was the forkhead family member, FoxH1 (previously FAST1) (Chen et al. 1996). The FoxH1-Smad2-Smad4 complex binds an activin-responsive element on the promoter region of Mix2 in response to activin/nodal-like signals during mesoderm specification in Xenopus. FoxH1 is essential for the binding of this complex to the Mix2 promoter (X. Chen et al. 1997; Liu et al. 1997). FoxH1 specifically interacts with the MH2 domain of Smads 2 and 3. This interaction is mediated by two separate sequences on FoxH1: a proline-rich sequence called the SIM and a FoxH1-specific motif (Germain et al. 2000). Three other forkhead family members, FoxO1, FoxO3, and FoxO4, serve as Smad3 transcriptional partners in the activation of the cyclin-dependent kinase inhibitor p21Cip1 or CDKN1A (Seoane et al. 2004). In this case, however, the interaction is mediated by the DNAbinding domain ("forkhead" or "Fox-box" domain) of the FoxO proteins and the MH1 domain of Smad3.

A region structurally and functionally similar to the FoxH1 SIM is also present in Mixer and Milk. However, these proteins are members of the Mix family of homeodomain transcription factors. Mixer and Milk serve as Smad partners in the regulation of Xenopus goosecoid (Germain et al. 2000). Interestingly, it has been suggested that the contact with the goosecoid promoter is established by Mixer or Milk with Smads tethered to these proteins without directly contacting the DNA /Germain et al. 2000).

Activation of Vent2 during ventral mesoderm differentiation in Xenopus is mediated by an OAZ-Smad1Smad4 complex in response to BMP (Hata et al. 2000). OAZ belongs to yet another family of DNA-binding proteins, the zinc-finger protein family. OAZ contains 30 zinc-finger motifs, some of which mediate binding to Smad1 and others mediate binding to a Vent2 promoter sequence (Hata et al. 2000). Another BMP target gene 
activated by the Smad-OAZ complex is Xretpos, a novel family of long terminal repeat (LTR)-retrotransposons in Xenopus, whose transcript is restricted to ventro-posterior-specific regions (Shim et al. 2002). However, the activation of the homeobox gene, Tlx2, by BMP in the mouse embryo during gastrulation and in the embryonic carcinoma p19 cell line (Macias-Silva et al. 1998; Tang et al. 1998) is not mediated by Smad-OAZ (Hata et al. 2000). In this case, the TRAF6-interacting protein Ecsit, which is also implicated in the Toll signaling pathway, helps the Smad1-Smad4 complex recognize Tlx2 for activation (Xiao et al. 2003). This provides yet another example of the level of selectivity that has evolved to ensure proper control of target gene selection in Smad transcriptional programs.

The list of DNA-binding partners is rapidly growing. The RUNX family of DNA-binding factors contributes three members to this list: Runx1 (also known as AML1/ CBFA2/PEBP2 $\alpha$ B, Runx2 (AML3/CBFA1/PEBP2 $\alpha A$ ), and Runx3 (AML2/CBFA3/PEBP2 $\alpha$ C) (Hanai et al. 1999; E. Pardali et al. 2000; Zhang and Derynck 2000; Alliston et al. 2001). TGF $\beta$-activated Runx-Smad2/3-Smad4 complexes target the $\operatorname{IgC} \alpha$ promoter in B cells (Hanai et al. 1999; E. Pardali et al. 2000; Zhang and Derynck 2000) and the osteocalcin promoter in osteoblasts (Alliston et al. 2001). AP1 transcription factors interact with Smads in the regulation of $c$-jun (Zhang et al. 1998), collagenase-I/MMP1 (Wong et al. 1999), and interleukin-11 (Y. Kang et al. 2005). While AP1 and Smad complexes have been shown to bind to adjacent sites on the collagenase$I / M M P 1$ and interleukin-11 promoters, they can act on the $c$-jun promoter by a long-range synergy from distant promoter sites (Wong et al. 1999). Thus, in the c-jun response, AP1 and Smads may not establish the kind of physical partnership that is characteristic of other Smadpartner interactions. The E2F family members E2F4 and E2F5 act as partners of Smad3-Smad4 in repression of $c-M y c$ by TGF $\beta$ in epithelial cells (Chen et al. 2002) and the ATF/CREB family member ATF3 in the repression of Id1 (Kang et al. 2003).

p53 has been proposed to interact with Smads and to be required for many Smad gene responses, although no direct physical interaction has been demonstrated (Cordenonsi et al. 2003). Among general transcription factors, Sp1 has been implicated in the induction of p15Ink4b (Feng et al. 2000) and p21Cip1 (K. Pardali et al. 2000), but no evidence has been provided yet that TGF $\beta$ controls the interaction of endogenous Sp1 with the p15Ink $4 b$ and p21Cip1 promoters in chromatin immunoprecipitation assays or that conditional depletion of Sp1 specifically interferes with the induction of these genes by TGF $\beta$.

It remains possible that genes containing enough clustered copies of the SBE in the promoter region might be activated by Smad-only complexes. One candidate in this class is Smad7, whose promoter contains two palindromic SBEs (Denissova et al. 2000). Smad7 is activated by both TGF $\beta$ and BMP pathways in many cell types for negative feedback. So, it would make sense if its induction could be achieved by activated Smads re- gardless of the activating input. Nevertheless, definitive proof for this notion is still lacking. Indeed, several reports show that full activation of the Smad7 promoter requires cooperation of the Smad complex with AP1, Sp1, or TFE3 transcription factors (Brodin et al. 2000; Hua et al. 2000). Of note, the p21Cip1 promoter contains up to four consecutive SBEs in the TGF $\beta$ responsive region, but still requires the participation of FoxO as a Smad partner (Seoane et al. 2004).

\section{Roles of Smads in transcriptional activation and repression}

Smad transcriptional complexes target specific genes for either induction or inhibition through the direct recruitment of transcriptional coactivators or corepressors to target promoters. However, other modalities of gene regulation appear to include Smad interference with activators or repressors, and Smad cooperation with DNAbinding partners that are themselves targets of Smaddependent expression. Groups of gene responses generated by these mechanisms constitute transcriptional programs for the regulation of specific cellular functions, as has been systematically explored in the TGF $\beta$ cytostatic response of epithelial cells (Siegel and Massagué 2003). Other properties of this system enable the generation of graded gene responses to TGF $\beta$ family morphogens and the synchronous expression-or "synexpression" —of functionally diverse genes by a common Smad complex.

\section{Smad-dependent transcriptional activation}

The ability of the MH2 domains of Smad1 and Smad4 to display transcriptional activation potential when tethered to DNA via a heterologous Gal4 DNA-binding domain (GBD) was recognized early on (Liu et al. 1996). A GBD fusion to the full Smad1 protein had little activity on its own, but showed strong BMP inducible transcriptional activity. This was presumably due to effects of BMP signaling on endogenous Smads, which entered the nucleus where they could interact with the tethered Smad1 fusion. This idea was backed up by the finding that the activity of GBD-Smadl fusions could be induced by coexpression of Smad4 (Liu et al. 1996, 1997). Domain mapping studies (Zhang et al. 1996; Hata et al. 1997), and later structural data (Shi et al. 1997; Chacko et al. 2004), demonstrated that the MH2 domains in response to TGF $\beta$ or BMP stimulation form a complex with transcriptional activation potential.

Much of the initial interest in Smad coactivators was focused on the general coactivators p300 and CBP (Massagué and Wotton 2000). In part this came from experiments using the adenovirus E1a protein, which on overexpression was known to titrate these factors. E1a expression inhibited Smad responses, whereas a mutant that lacked the p300/CBP-binding domain had no effect (Feng et al. 1998; Pouponnot et al. 1998; Shen et 
al. 1998; Topper et al. 1998). p300 and CBP interact with Smads 1, 2, 3, and 4, and these interactions mapped to the MH2 domains. These findings, together with the demonstration that Smads had sequence-specific DNAbinding activity, firmly identified the Smad proteins as classical transcription factors, with a modular structure, including the MH1 DNA-binding domain and the MH2 oligomerization and transcriptional activation domain (Figs. 3, 4A).

The fact that $\mathrm{p} 300 / \mathrm{CBP}$ coactivator complexes contain multiple activities that are capable of acetylating histone N-terminal tails (Bannister and Kouzarides 1996; Ogryzko et al. 1996) suggested that Smads function in part by remodeling the chromatin template, an idea that has been further supported by the identification of histone deacetylases (HDACs) as alternate components of Smad complexes (see below). The recruited acetylase activity might also act on other chromatin-associated proteins, including the Smads themselves. However, although many transcription factors are acetylated, there is currently no evidence for direct acetylation of either Smad4 or the RSmads.

Interaction of the Smad proteins with such general coactivators also provided for the possibility of integration of different signals at the level of the coactivators, a form of nuclear cross-talk between signal transduction pathways. Indeed, the ability of BMP2 and LIF (leukemia inhibitory factor) to synergistically induce astrocyte differentiation was shown to result from the simultaneous binding of their signal transducers, Smad1 and STAT3, respectively, to separate sites in p300 to cooperatively activate the glial fibrillary acidic protein promoter (Nakashima et al. 1999). This may provide a model, not only for how two signals can be integrated in the nucleus, but also for how more specificity of transcriptional activation can be generated.

Smads reportedly interact with other general transcriptional regulatory proteins. The P/CAF chromatin assembly factor, which associates with p300/CBP complexes, was shown to interact with the $\mathrm{MH} 2$ domain of TGF $\beta$-activated RSmads, and some potentiation of a TGF $\beta$ transcriptional response was seen with increased P/CAF expression (Itoh et al. 2000). The ARC105 component of the Mediator complex interacts with Smads 2, 3, and 4, again via the MH2 domain (Kato et al. 2002). This interaction was shown, by siRNA knock-down, to be required for full activation of TGF $\beta$ (but not BMP) transcriptional responses in Xenopus.

In addition to these general transcriptional coactivators, more specific Smad coactivators have been identified, many from yeast two-hybrid interaction screening. Deletion analysis of Smad4 revealed the presence of a transcriptional activation domain, named the SAD, at the C-terminal end of the linker region extending into the MH2 domain (de Caestecker et al. 2000). Subsequent analysis suggested that the protein MSG1 promotes interaction of p300 with Smad4, primarily via the SAD (Figs. 3, 4A; Shioda et al. 1998; Yahata et al. 2000). Thus, MSG1 may represent a type of specificity factor, which is not absolutely required, but can promote preferential in- teraction of a general coactivator with a specific transcription factor, in this case p300 with Smad4.

Other transcriptional coactivators that appear to be more Smad-specific, or at least less general in their effects, include SMIF and Swift. SMIF is a Smad4-interacting cofactor that is present in the cytoplasm and accumulates in the nucleus with the Smads in response to either TGF $\beta$ or BMP signals (Bai et al. 2002). Like MSG1, SMIF on its own is not a transcriptional activator, but interacts with both Smad4 (via the SAD) and p300, and potentiates TGF $\beta$-activated gene expression. Swift is a Xenopus BRCT (BRCA1 C-terminal) domain-containing protein that interacts with $\mathrm{Smad} 2$ and enhances activin signaling during early development (Shimizu et al. 2001). Whether Swift acts by recruiting general coactivators is not known, but it does appear to be a potent transcriptional activator.

\section{Smad-mediated gene repression}

Although Smad proteins have intrinsic transcription-inducing activity, there are also many examples of genes that are transcriptionally repressed by Smads. The repression of $c-M y c$ in the context of the TGF $\beta$ cytostatic response was the first major example of this type of effect (Siegel and Massagué 2003). With the advent of microarray-based transcriptomic assays, it became clear that at least one-quarter of all TGF $\beta$ gene responses in mammalian cells are gene repression responses (Chen et al. 2001; Zavadil et al. 2001; Kang et al. 2003).

The inhibitory effect of TGF $\beta$ on $c-M y c$ expression is rapid and occurs in most cell types that are growth inhibited by TGF $\beta$. Promoter analysis identified a TIE within the proximal $c-M y c$ promoter, which is required for TGF $\beta$-induced transcriptional down-regulation in epithelial cells. The $c$-Myc TIE binds a complex consisting of Smad3 and Smad4, together with a heterodimer of E2F4 or 5 and DP1 (Fig. 4B; Chen et al. 2002; Frederick et al. 2004). Both of these heteromeric DNA-binding complexes contact DNA, via Smad- and E2F-binding sites within the TIE. What makes this a repressive complex is that the corepressor p107 is bound via contacts with both E2F4/5 and Smad3 (Chen et al. 2002). Despite the presence of more widely acting Smad transcriptional corepressors such as TGIF and Ski (see below), it is the presence of this very specific complex that allows for down-regulation of $c-M y c$.

In human keratinocytes, E2F proteins also play a role in TGF $\beta$-induced repression of the Cdc25A tyrosine phosphatase, which is an activator of cyclin-dependent kinases. However, this repression is a secondary gene response mediated by the accumulation of E2F4-p130 HDAC complexes in cells that have undergone exit from the cell cycle (Iavarone and Massagué 1999). In mammary epithelial cells, repression of $C d c 25 A$ by TGF $\beta$ appears to be an immediate gene response that occurs through an as yet unknown mechanism (Iavarone and Massagué 1997).

Transcriptional profiling of epithelial cells demonstrated that expression of the $I d 1, I d 2$, and $I d 3$ inhibitors 
of differentiation was repressed on treatment with TGF $\beta$ (Fig. 4C; Kang et al. 2003). Repression of Id1 requires binding of ATF3 and Smad3 to specific promoter elements, where ATF3 mediates transcriptional repression. TGF $\beta$ elevates expression of ATF3 in a first-wave response, and then Smad3 and ATF3 cooperatively repress Id1 expression (Kang et al. 2003). Like repression of $c$ $M y c$, this is clearly a situation in which direct promoter binding by a TGF $\beta$-activated Smad complex mediates repression of gene expression, again by a specialized mechanism. In contrast, repression of Id2 by TGF $\beta$ in keratinocytes is secondary to down-regulation of c-Myc or induction of the Mad family of c-Myc antagonists (no relationship to the Smad1 orthologene in Drosophila, also named Mad) (Siegel et al. 2003).

Smad3 is also able to repress specific responses by recruiting class II histone deacetylases, such as HDAC4 (J.S. Kang et al. 2005). Smad3 interacts with the Runt domain transcription factor, Runx2, and inhibits its ability to activate the osteocalcin promoter (Alliston et al. 2001). This effect of Smad3 is both cell type and promoter specific. In part this specificity may come from the fact that HDAC4 itself is able to interact with Runx2 (Vega et al. 2004), again suggesting the formation of a specific Smad-containing repressor complex that targets certain gene responses.

Examples of Smad-mediated gene repression have also been defined in BMP pathways. Nkx3.2 is a DNA-binding transcriptional repressor that regulates chondrocyte differentiation under control of BMP signaling (Kim and Lassar 2003). Nkx3.2 interacts with the mSin3/HDAC complex in a Smad1/Smad4-dependent manner (Fig. 4B). It appears that both the Smad complex and Nkx3.2 contact HDAC1 or 2, but that interaction of $\mathrm{Nkx} 3.2$ with Smad1 is required for recruitment of the mSin3/HDAC complex. The Mad-Medea (Smad1-Smad4) complex in Drosophila mediates the activation of numerous gene responses in response to the BMP-like factor, Dpp (Massagué 1998; Raftery and Sutherland 1999). However, binding of the Mad-Medea complex to a particular element of the Brinker promoter allows the preferential recruitment of the repressor Schnurri to cause repression (Marty et al. 2000; Muller et al. 2003). The sequence of these Mad-Medea-binding silencers differs from the normal Dpp response element, and it is thought that this allows for recruitment of Schnurri.

\section{Transcriptional deactivation and derepression}

Smad proteins can also inhibit gene expression by preventing the action of transcriptional activators. The inhibitory effect of TGF $\beta$ on skeletal muscle differentiation has been suggested to result from an interference of Smad3 with the myogenic differentiation transcription factor MyoD (Liu et al. 2001). In response to TGF $\beta$, Smad3 can interact with the basic helix-loop-helix (bHLH) domain of MyoD, preventing it from forming MyoD-E12/47 dimers and binding to E-box response elements in genes critical for myogenic differentiation (Liu et al. 2001). Here, Smad3 inhibits gene expression by preventing a transcription factor from exerting gene activation. A second mechanism for inhibition of myogenic differentiation has been proposed, in which Smad3 binds to another inducer of differentiation, the transcription factor MEF2, blocking its interaction with the coactivator GRIP-1 (Liu et al. 2004). Interestingly, Smad3, but not Smad2, is implicated in these inhibitory effects of TGF $\beta$. Other reports of TGF $\beta$ interfering with the action of transcription factors also point at Smad3 as the mediator of these effects (for example, Alliston et al. 2001). Thus it may be that this is a specific role of Smad3. Nonetheless, the significance of these observations in cell culture remains unknown because no major defect in muscle formation has been described to date in various Smad3-null mouse models.

Certain gene responses to TGF $\beta$ family signals occur in part by the ability of Smad proteins to displace transcriptional repressors from a target gene promoter. For example, Dpp signaling in Drosophila relieves repression of a subset of genes by inhibiting expression of the transcriptional repressor Brinker (Marty et al. 2000; Muller et al. 2003). Brinker competes with Mad for binding to overlapping sites in specific Dpp-responsive elements, in genes such as Zen and ultrabithorax (Ubx) (Fig. 4C; Kirkpatrick et al. 2001; Rushlow et al. 2001). By repressing the expression of the repressor Brinker, Dpp signaling favors the action of Mad-Medea and allows the expression of Zen and $U b x$.

\section{Self-enabled gene responses}

The way in which Zen and $U b x$ are activated by MadMedea also represents an example of what can be called "self-enabled" gene responses, meaning gene responses that are mediated by Smad proteins depending on prior Smad-mediated gene responses (Fig. 4C). Other examples of this mode of activation involve the Smad-mediated expression of DNA-binding cofactors that then act as partners of Smad complexes to regulate the expression of new target genes. Such gene responses could be considered secondary in that they require new protein synthesis (synthesis of the DNA-binding cofactor) but could also be considered primary gene responses in that they involve the direct action of a TGF $\beta$-activated Smad complex on the gene promoter in question.

In Xenopus, nodal-like signals acting via Smad2/3Smad4 induce the expression of Mixer /Germain et al. 2000), which then forms a Mixer-Smad2/3-Smad4 complex that binds to the goosecoid promoter to activate gene transcription (Fig. 4C). Another example-a repression response, in this case-is provided by the TGF $\beta$ dependent inhibition of Id1 expression in mammalian epithelial cells (Kang et al. 2003). A TGF $\beta$-activated Smad3-Smad4 complex binds to the TGF $\beta$ responsive region of the $I d 1$ promoter, initially causing a burst of transcriptional activation. In the meantime, other Smad3-Smad4 complexes bind to the ATF3 promoter to induce expression of ATF3, which is a transcriptional repressor (Fig. 4C). As it accumulates, ATF3 becomes recruited by Smad3-Smad4 to the Id1 promoter, causing 
Id1 repression (Kang et al. 2003). Thus, by specifically inducing the expression of a Smad transcriptional partner, TGF $\beta$ modifies the cellular context to enable repression of the Id1 gene. By requiring the consecutive activation of two transcription factors-Smad and ATF3and coupling the activation of one to that of the other, this mechanism provides tight transcriptional control.

Self-enabled gene responses have built-in devices for the differential interpretation of effects of transient versus sustained TGF $\beta$ stimuli. For example, as a TGF $\beta$ dependent gene response that requires the TGF $\beta$-induced expression of a Smad partner first, Id1 repression contains a built-in time gap. Id1 repression requires a sufficiently prolonged TGF $\beta$ signal that would not be achieved by a brief exposure of the cells to TGF $\beta$.

\section{Integrated gene responses}

Self-enabled gene responses may additionally provide a mechanism for the integration of TGF $\beta$ transcriptional programs. An example is provided by the induction of p15Ink4b and p21Cip1 cyclin-dependent kinase inhibitors, which is enabled by the down-regulation of $c-M y c$ (Fig. 4C). c-Myc, in complex with Myc-interacting zincfinger protein-1 (Mizl), binds to a proximal promoter region of $p 15 \operatorname{Ink} 4 b$ and $p 21$ Cip1, inhibiting the expression of these genes (Seoane et al. 2001; Staller et al. 2001). Down-regulation of $c-M y c$ by TGF $\beta$ relieves $p 15 \operatorname{Ink} 4 b$ and p21Cip1 from c-Myc-Miz1-mediated repression (Seoane et al. 2001, 2002), enabling activation of these genes by Smad-FoxO complexes bound to an upstream Smad-responsive region (Seoane et al. 2004). Therefore, the induction of $p 15 \operatorname{Ink} 4 b$ and $p 21$ Cip 1 by TGF $\beta$ is based on two inputs, one involving direct transactivation delivered by a Smad-FoxO complex, and the other involving a derepression by down-regulation of $c-M y c$. This second input, which enables transcriptional activation by Smad-FoxO, additionally integrates the $c-M y c$, $p 15 \operatorname{Ink} 4 b$, and $p 21$ Cip1 responses in the TGF $\beta$ cytostatic program. As each of these gene responses has an impact on cell cycle progression, their coordinated execution may help ensure an orderly attenuation of CDK and cMyc activities in epithelial cells undergoing cell cycle arrest in response to TGF $\beta$.

\section{Graded Smad responses to morphogens}

Organization of cell and body patterns is controlled by gradients of cytokines referred to as "morphogens". In these contexts, different sets of target genes are induced depending on the concentration of the morphogen. TGF $\beta$ family members, including Dpp, certain BMPs, nodals, and activins, are thought to act as morphogens during embryonic development (Hogan 1996; Whitman 1998). Different concentrations of these factors lead to different levels of receptor occupancy and hence varying levels of activated Smads in the nucleus (Dyson and Gurdon 1998). It is conceivable that the different affinity of DNA-binding partners and target promoters for the acti- vated Smad core complex dictate which Smad target promoters will be activated at low concentrations of agonist and which at higher concentrations.

The nature of self-enabled gene responses, with their capacity for the differential interpretation of weak and transient versus more robust and sustained stimuli, provides a potential mechanism for the interpretation of morphogen gradients. One example of this is suggested by Dpp, which generates a graded expression pattern that is crucial for the proper development of Drosophila. In the developing wing imaginal disc of Drosophila, a key player is the transcriptional repressor Brinker. Its expression is finely controlled by the intensity of Dpp signaling through a morphogen-regulated silencer present in the Brinker promoter (Marty et al. 2000). A Smad complex containing the DNA-binding cofactor Schnurri binds to the silencer region in the Brinker promoter to control its expression, depending on the intensity of the signal. Schnurri allows the Smad complex to sense different intensities of Dpp signaling and hence generate graded transcriptional expression in response to a morphogen.

During Xenopus development, an activin-like signaling gradient (most likely formed by Xnr nodal homologs) has been proposed to govern mesoderm formation. In individual cells, the specific sets of genes activated in response to the activin-like signal depend on the position of the cell within the gradient and the absolute number of occupied receptors on the cell surface (Dyson and Gurdon 1998). Based on these in vitro experiments with animal cap explants, it has been proposed that the magnitude of a cell's response to activin is determined by the rate of entry of phosphorylated Smad2 into the nucleus (Bourillot et al. 2002). As with other TGF $\beta$ family responses, this links the magnitude of the transcriptional response to the level of activin sensed by the cell. It should be noted that these studies largely relied on the use of an artificial system (animal cap explants) and need to be validated in the context of the whole embryo.

\section{Smad synexpression groups}

It has long been recognized that certain groups of genes are expressed in a seemingly coordinated manner in the same tissue and with the same kinetics (Gawantka et al. 1998; Niehrs and Pollet 1999; Niehrs and Meinhardt 2002). Such synchronously coexpressed gene sets, or "synexpression" groups, are particularly apparent during embryo development (Tsang et al. 2002; Baldessari et al. 2005) and in the response of cells to specific hormones and growth factors (Karaulanov et al. 2004). The genes in a particular synexpression group may encode functionally diverse activities. However, their joint expression suggests that such activities act in a complementary fashion to achieve a programmed developmental event or a balanced response to a stimulus.

The biological significance of this phenomenon may be profound but its mechanistic basis remains largely unknown. In a simple scenario, the set of genes in question would contain the same cognate sequence for a transcription factor and thus would respond together to that 
factor. In synexpression groups controlled by TGF $\beta$ family signals, the transcription complex in question would be a particular cofactor-RSmad-Smad4 combination. A BMP4 synexpression group in Xenopus has been analyzed with this possibility in mind (Karaulanov et al. 2004). Three of the genes representing this group are bambi, smad7, and vent2. In vent2, BMP4-dependent induction is mediated by binding of a OAZ-Smad1-Smad4 complex to a distinct BRE in this promoter (Hata et al. 2000; Karaulanov et al. 2004). The BMP4 synexpression promoter module defined in bambi, smad7, and other genes in this synexpression group involves a region containing an SBE, a conserved GC-rich BRE (5'-TGGC GCC-3'), and a Vent2 site, but no OAZ site (Karaulanov et al. 2004). So, it appears that BMP-activated Smads with OAZ induce Vent2, and Vent2 then cooperates with BMP-activated Smads to induce the expression of bambi, Smad7, and other genes in the synexpression group (Fig. 4C).

These complexities may limit the ability to predict potential Smad-responsive genes through bioinformatic analysis of gene promoter regions. Gene expression profiling of TGF $\beta$ response in cells depleted of specific Smad cofactors holds promise as an alternative approach to identifying specific TGF $\beta$ synexpression groups.

\section{Constraining Smad transcriptional functions}

Several types of mechanisms have evolved to limit the activity of Smad transcription factors (Fig. 5). One type includes transcriptional corepressors that interfere with the ability of Smads to engage coactivators. The homeodomain protein TGIF was identified in a screen for Smad2-interacting proteins and was shown to be a transcriptional repressor that inhibits TGF $\beta$ signaling (Wotton et al. 1999a). TGIF interacts specifically with Smad2 and Smad3 and recruits a complex of general corepressors, including CtBP and the mSin3/HDAC complex (Wotton et al. 1999b; Melhuish and Wotton 2000). Binding of TGIF prevents the interaction of Smads with co- activators, such that activation of target gene expression is reduced. The resulting competition for Smad binding between coactivators and corepressors helps determine the magnitude of the transcriptional output from a given level of signaling. A second TGIF-related protein (TGIF2) also has Smad transcriptional corepressor activity, and TGIF homologs, which are also Smad corepressors, are found in other vertebrate species (Melhuish et al. 2001; Hyman et al. 2003).

Interestingly, mutations in human TGIF are associated with holoprosencephaly (HPE), a severe genetic disease affecting craniofacial development, in which the primary defect is a failure of ventral forebrain development (Gripp et al. 2000). One point mutation identified in an HPE patient specifically prevents interaction of TGIF with the corepressor CtBP, suggesting that the ability of TGIF to carry out its function as a transcriptional corepressor is critical for forebrain development (Melhuish and Wotton 2000). There is evidence from mouse models and zebrafish that mutations affecting TGF $\beta$ signaling can cause HPE-like phenotypes (Hayhurst and McConnell 2003), suggesting that over- or underactivity of TGF $\beta$ family signaling during embryogenesis can perturb normal craniofacial development. The Smad corepressor, Ski (see below) has also been shown to regulate craniofacial development. A mouse knock-out of Ski resulted in perinatal lethality, with a high frequency of exencephaly and facial clefting, due to a failure of neural tube closure (Berk et al. 1997). The phenotypes of the Ski-null mice have been suggested to be analogous to the human 1p36 deletion syndrome, and the human Ski gene is located on chromosome 1p36 (Colmenares et al. 2002).

The proto-oncoprotein Ski and the related protein SnoN are transcriptional corepressors for TGF $\beta$-activated Smads (Fig. 5). Both Ski and SnoN were isolated biochemically as Smad4-interacting proteins, and were also shown to bind Smad2 and 3 (Akiyoshi et al. 1999; Luo et al. 1999; Stroschein et al. 1999; Sun et al. 1999a). It has been reported that Ski, but not SnoN, can also

Figure 5. Mechanisms that constrain Smad signaling. Principal examples of protein-protein interactions and post-translational modifiers that negatively control signaling by the Smad pathway.

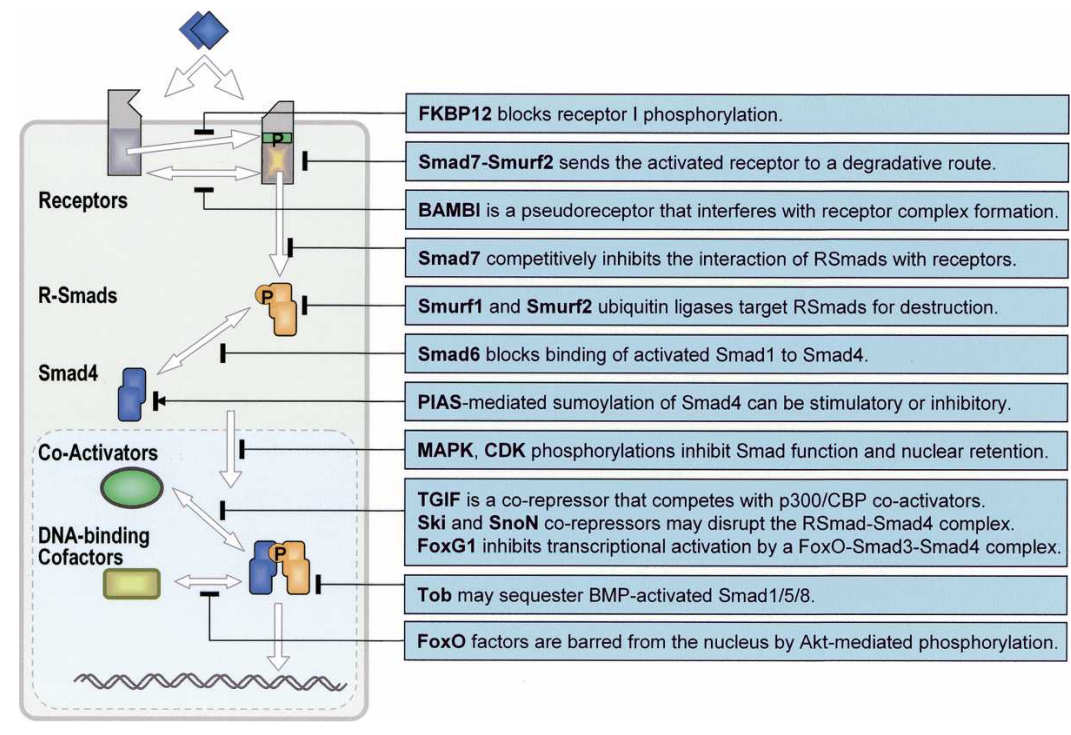


interact with Smads 1 and 5 (Wang et al. 2000), although this interaction appears not to be sufficient for repression of a BMP response (Takeda et al. 2004). Ski interacts with the $\mathrm{N}-\mathrm{CoR} / \mathrm{mSin} 3 / \mathrm{HDAC}$ repressor complex (Nomura et al. 1999). Initially, Ski and SnoN were thought to act much like TGIF, being recruited to a TGF $\beta$-activated Smad complex with corepressors including $\mathrm{N}-\mathrm{CoR}, \mathrm{mSin} 3$, and HDACs. Indeed, it was shown that Ski was able to recruit $\mathrm{mSin} 3$ and HDAC1 to Smad3 and could compete with p300 for binding to Smad3 (Luo et al. 1999). However, this is unlikely to be the whole story and may not even be the main way in which Ski represses TGF $\beta$ signaling. It has been shown that Ski interacts with Smad4 via the same region of the MH2 domain that is required for interaction with $\operatorname{Smad} 2$ and Smad3, and competition between Smad2 and Ski for binding to Smad4 was demonstrated (Wu et al. 2002). This results in a model in which Ski, and presumably the structurally related SnoN, can prevent the formation of an active Smad complex. However, an additional Smad2/3 interaction domain was mapped within Ski and SnoN, and although this appears to have a lower affinity for Smads, it may still inhibit Smad function without disrupting Smad complex formation (Luo et al. 1999; Stroschein et al. 1999). Both Ski and SnoN are expressed at relatively low levels and can undergo Smad-targeted ubiquitination and degradation (Sun et al. 1999b; Bonni et al. 2001; Stroschein et al. 2001). Additionally, SnoN expression is transcriptionally up-regulated by TGF $\beta$ (Stroschein et al. 1999). Thus, these various events may generate a rich negative feedback loop to limit the duration of the Smad response.

Evi-1 is a zinc finger containing proto-oncoprotein implicated in the leukemic transformation of hemopoeitic cells (Lopingco and Perkins 1996). Evi-1 was initially shown to bind to Smad3 and inhibit its ability to bind to DNA, preventing TGF $\beta$-induced growth inhibition (Kurokawa et al. 1998). However, full repression of a Smad3-dependent transcriptional response required regions of the Evi-1 protein other than the domain that blocked DNA binding. Later work demonstrated that Evi-1 interacts with the corepressor protein CtBP and that this interaction is required for full repression of a TGF $\beta$ response (Izutsu et al. 2001). In addition, HDAC has been implicated in repression by Evi-1 (Izutsu et al. 2001). This suggested that Evi-1 is a Smad transcriptional corepressor, much like TGIF (which also recruits CtBP) and Ski/SnoN.

The fact that Evi-1 and Ski were independently identified as proteins with oncogenic potential raises the possibility that overexpression of Smad transcriptional corepressors may contribute to tumorigenesis by preventing the growth inhibitory effects of TGFß. Evi-1 is a component of the AML/Evi-1 fusion gene generated by a 3;21 chromosomal translocation (Lopingco and Perkins 1996). These fusions express the entire Evi-1 protein fused to the DNA-binding (Runt) domain of AML1. Among the possible explanations for how this fusion protein contributes to hematopoietic stem cell malignancies is the possibility that overexpression of Evi-1 as part of the fusion inhibits TGF $\beta$ signaling. v-Ski, which contains a small C-terminal truncation relative to its cellular counterpart, was identified from an avian retrovirus and shown to cause fibrosarcoma (Stavnezer et al. 1986). It appears that v-Ski overexpression, rather than truncation, is what transform cells, suggesting increased rather than altered function (Colmenares et al. 1991). Thus, increased Ski expression might be expected to contribute to tumorigenesis by blocking TGF $\beta$ growth inhibitory signals. Indeed, the transforming ability of Ski is dependent on its ability to inhibit TGF $\beta$ signaling (He et al. 2003). Although there is no evidence that TGIF is an oncogene, it is amplified in a subset of esophageal tumors, and cell lines derived from these tumors are more resistant to TGF $\beta$ growth inhibition (Nakakuki et al. 2002). The related gene TGIF2 may also be amplified in some ovarian tumors (Imoto et al. 2000). Thus, it may be that the amplification or overexpression of negative regulators of TGF $\beta$ activated transcription is a common theme in tumorigenesis, even if it is not a primary event.

\section{Other inhibitory interactions}

The interaction of other regulatory proteins with either the Smads themselves or with their coactivators results in decreased gene expression by interfering with the formation of transcriptional activation complexes. A case in point is the inhibitor of TGF $\beta$ signaling SNIP1, which interacts with Smad4 and p300 and is thought to prevent the formation of a functional Smad-p300 complex (Kim et al. 2000). In contrast to Smad transcriptional corepressors, which also compete with general coactivators for Smads, SNIP1 appears not to recruit corepressor proteins.

Another example is provided by the bHLH transcription factor neurogenin, which has been proposed to inhibit expression of glial differentiation genes by sequestering a Smad1-p300 complex away from DNA-bound STAT1/3 at glial-specific promoters (Sun et al. 2001). Neurogenin can also recruit the Smad1-p300 complex to neurogenin-binding sites in neuronal gene promoters resulting in their activation (Sun et al. 2001). The sequestration of Smad1-p300 from STATs is independent of the ability of neurogenin to bind to its own DNA site, suggesting that it is a separate repressive function. MdmX (Kadakia et al. 2002) and FoxG1 (Seoane et al. 2004) have also been proposed to disrupt transactivation by Smad complexes.

Other inhibitors may act by binding Smad proteins and barring their access to transcriptional regulators. Mice with a targeted deletion in the gene encoding the anti-proliferative protein Tob have increased bone mass and increased bone formation in response to BMP2 (Yoshida et al. 2000). Tob has been proposed to sequester BMP-activated Smads (Yoshida et al. 2000), but it has also been proposed to interact with Smads 6 and 7 and to localize to the plasma membrane (Yoshida et al. 2003). Thus, Tob is capable of affecting BMP signaling, but its precise mechanism of action is unclear. In a related example, mutations in the gene LEMD3 are responsible for 
diseases of increased bone density in humans (Hellemans et al. 2004). This gene encodes MAN1, an integral inner nuclear membrane protein that binds and sequesters RSmad proteins, inhibiting their activation and association with Smad4 (Pan et al. 2005).

\section{Roles of the inhibitory Smads}

The inhibitory Smads include Smad6 and Smad7 in vertebrates (Hayashi et al. 1997; Imamura et al. 1997; Nakao et al. 1997; Hata et al. 1998) and Dad in Drosophila (Tsuneizumi et al. 1997). The MH2 domain of Smad6 and Smad7 is thought to have a similar overall structure to that of Smad4 or RSmads lacking the C-terminal sites for receptor-mediated phosphorylation. Smad7 inhibits TGFß/activin and BMP signaling (Hayashi et al. 1997; Nakao et al. 1997), whereas Smad6 inhibits primarily the BMP pathway (Imamura et al. 1997; Hata et al. 1998). It should be noted that high-level overexpression of either Smad6 or Smad7 results in inhibition of both TGF $\beta$ and BMP signaling, blurring the distinctions in Smad6 and Smad7 function.

Smad6 competes with Smad4 for interaction with the receptor-activated Smad1, such that inactive Smad1Smad6 complexes are formed (Hata et al. 1998). Thus, receptor-activated Smad1 is sequestered away from forming active complexes with Smad4 (Fig. 5). Targeted disruption of the Smad6 gene in mice revealed defects consistent with an increase in BMP signaling, primarily in the cardiovascular system, where Smad6 expression appears to be highest (Galvin et al. 2000). A repressive role for Smad6 in the nucleus has been proposed, and recent evidence suggests that a Smad6 interaction with the corepressor CtBP is required for this function (Bai et al. 2000; Lin et al. 2003c). Smad6 does contain a CtBP interaction motif, and an interaction is detectable, but it remains to be determined whether this is a true role of Smad6, and if so, how it is recruited to target promoters.

Smad7 binds to activated TGF $\beta$ and BMP receptors in competition with RSmads (Fig. 5; Hayashi et al. 1997; Nakao et al. 1997). In Xenopus, Smad7 appears to be able to regulate both BMP and TGF $\beta$ signaling by this mechanism, and may in fact preferentially target BMP receptors (Bhushan et al. 1998; Casellas and Brivanlou 1998; Souchelnytskyi et al. 1998). In Drosophila, Dad was shown to antagonize Dpp signaling (Tsuneizumi et al. 1997), but from overexpression experiments in transgenic flies, has also been suggested to have a potential role in Drosophila activin signaling (Marquez et al. 2001).

In addition to its roles as a competitive inhibitor, Smad7 has been shown to play an important, and perhaps principal, role in regulating TGF $\beta$ receptor ubiquitination by Smurf ubiquitin ligases (Fig. 5; Kavsak et al. 2000; Suzuki et al. 2002). Smurf2 can bind to Smad7, resulting not in immediate ubiquitination and degradation of Smad7, but in export to the cytoplasm. The Smurf-Smad7 complex is then able bind to the TGF $\beta$ receptor complex and promote its ubiquitination, thereby down-regulating signaling (Kavsak et al. 2000;
Suzuki et al. 2002; Tajima et al. 2003). BMP receptors are also targeted for degradation in this manner, and it appears that Smurf1, as well as Smads 6 and 7, plays a role (Murakami et al. 2003).

The activity of Smad6 and Smad7 is regulated at many levels, suggesting that they are key points for fine-tuning the responses to TGF $\beta / \mathrm{BMP}$ signaling. Smad7 expression is induced by TGF $\beta$, activin, and BMP signaling (Nakao et al. 1997; Ishisaki et al. 1998; Benchabane and Wrana 2003) and likely plays an important role in a negative feedback loop to limit the duration of the signal. Similarly, Smad6 expression can be induced by BMP signaling (Afrakhte et al. 1998; Ishida et al. 2000). Direct binding of Smads to the Smad6 and Smad7 promoters has been shown to mediate these responses (Brodin et al. 2000; Denissova et al. 2000; Hua et al. 2000; Ishida et al. 2000; Stopa et al. 2000; von Gersdorff et al. 2000). Intriguingly, Smad7 normally resides in the nucleus and moves to the cytoplasm in response to TGF $\beta$, suggesting that TGF $\beta$ not only enhances expression of Smad7 transcription but also mobilizes a pre-existing nuclear pool of Smad7 to inhibit TGF $\beta$ receptors (Itoh et al. 1998). Smad7 expression can also be induced by other signaling inputs, which interfere with TGF $\beta$ signaling. In the immune system, where pathogenic and inflammatory signals counteract the effects of TGF $\beta$, Smad7 expression is activated by interferon $\gamma$ (Ulloa et al. 1999), tumor necrosis factor $\alpha$, and interleukin-1 $\beta$ (Bitzer et al. 2000).

\section{Regulation of Smads by phosphorylation of the linker region}

Phosphorylation of the C-terminal serine residues of the MH2 domain by activated receptor is not the only phosphorylation event controlling RSmad activity. The RSmad linker region contains multiple serine and threonine consensus sites for ERK MAP kinases (PxS/TP sites) and for proline-directed kinases in general. Extensive phosphorylation of these sites by endogenous kinases, including ERKs, is readily apparent in tissue culture (Kretzschmar et al. 1997, 1999). In vitro, several of these sites can be specifically phosphorylated by Erk1 and Erk2 in the case of Smad1, Smad2, and Smad3 (Kretzschmar et al. 1997, 1999|. ERK-mediated phosphorylation of Smads 1,2 , and 3 was shown to attenuate the nuclear accumulation and signaling activity of these proteins in response to agonists (Kretzschmar et al. 1997, 1999), the extent of this effect depending on the cell type.

Smad3 has been shown to also serve as a substrate of the G1 cyclin-dependent kinases Cdk2 and Cdk4. The CDK phosphorylation sites in Smad3 include threonine and serine residues in the linker region (Matsuura et al. 2004), which are also sites for ERK MAP kinases (Kretzschmar et al. 1997, 1999). As in the case of ERKmediated phosphorylation, CDK-mediated phosphorykation correlates with a decrease in Smad3 signaling activity (Matsuura et al. 2004). A similar effect has been reported for the phosphorylation of Smad2 by the calcium-calmodulin-dependent protein kinase-II at a distinct site in the linker region (Wicks et al. 2000). 
Unlike the structural and functional conservation of the $\mathrm{MH} 1$ and $\mathrm{MH} 2$ domains, the linker region of RSmads is rather divergent, providing a basis for selective regulation by upstream signals. Although the functional consequences of Smad linker phosphorylation can be acute and provide a direct tie between Smads and several key pathways, the molecular events triggered by these phosphorylations and their dependence on the cellular context remain a mystery. Yet, these events provide the most direct link between Smad proteins and several key pathways. Resolving how linker phosphorylation regulates Smad function will clarify signal integration by Smad proteins and their inhibition in cancer.

\section{Regulation of Smads by ubiquitination and acetylation}

Smad1 and Smad2 were the first Smads reported to be ubiquitinated, and like the classical ubiquitin-mediated regulation of protein function, this resulted in their targeting to the $26 \mathrm{~S}$ proteasome for degradation (Lo and Massagué 1999; Zhu et al. 1999). Following an initial accumulation in response to TGF $\beta$, receptor-phosphorylated Smad2 is eliminated by the acute action of a phosphatase(s) (Inman et al. 2002), but also by the slower action of ubiquitin-dependent proteasome degradation (Lo and Massagué 1999). It is possible that these two mechanisms operate to different extents on different pools of phosphorylated Smad complexes that mediate acute or prolonged gene responses.

In contrast to the signal-induced ubiquitination of Smad2, Smad1 was initially shown to be targeted for destruction by the HECT-domain E3 ligase, Smurf1, in the absence of BMP signaling (Zhu et al. 1999). Thus, cells with a high level of Smurf1 would have a lower steady-state level of Smad1 and, therefore, a lower response to BMP signals (Fig. 5). This kind of ubiquitindependent regulation by Smurfl can set the maximal possible response to BMPs and plays an important role in embryonic pattern formation in Xenopus and likely in other organisms (Zhu et al. 1999; Izzi and Attisano 2004). Thus, RSmad regulation by the ubiquitin/proteasome pathway occurs in both the basal and activated state, setting the maximal response in a particular cell by modulating the overall level of the Smad, and turning down the response once an initial burst of activation has occurred. Although these different modes of regulation were first uncovered separately for the TGF $\beta$ and BMP pathways, constitutive and signal-induced ubiquitination may play roles in both TGF $\beta$ and BMP signaling.

Other Smurf family members have been identified. dSmurf regulates BMP signaling during embryogenesis in Drosophila (Podos et al. 2001), and mammalian Smurf2 targets Smads 1, 2, and 3 (Izzi and Attisano 2004). A related protein, Tiul1 (for TGIF-interacting ubiquitin ligase), was proposed to regulate TGF $\beta$ signaling by causing the degradation of Smad2 (Seo et al. 2004). It appears that a complex of Smad2, TGIF, and Tiul1, in which all proteins are in contact with each other, is required for Smad2 ubiquitination. This would represent an alternate mode of inhibition of TGF $\beta$ signaling by the corepressor
TGIF. All of the Smurf family members contain a Cterminal HECT domain (for homologous to E6AP C terminus, a founding member of this superfamily). In addition, Smurfs contain an N-terminal C2 phospholipidand calcium-binding domain and a variable number (2-4) of WW protein interaction domains. By means of the WW domains, Smurfs interact with a specific motif in the linker region of the RSmads, termed the PY motif (PPXY) (Fig. 3; Izzi and Attisano 2004). Smad4 does not contain a PY motif and is not directly targeted by Smurfs, although it may become ubiquinated by Smurfs when bound to RSmads (Moren et al. 2005). In addition to their roles in regulating the levels of RSmads and Smad4, Smurfs target other components of these pathways for degradation, including corepressors, Smad4, the I-Smads, and the TGF $\beta$ and BMP receptors.

Other ubiquitin ligases, including SCF/Roc1, NEDD42, and HsN3, can target Smads for degradation, suggesting that the regulation of Smad stability is a critical feature of modulation of the responses to TGF $\beta$ and BMP signaling (Izzi and Attisano 2004). Activated Smad3 can be bound by the SCF/Roc1 E3 complex, which results in Smad3 export from the nucleus and its degradation in the cytoplasm (Fukuchi et al. 2001). Ubiquitination of activated Smad2 also requires its nuclear localization, but whether it is exported prior to degradation is not known (Lo and Massagué 1999). There is evidence for Smad4 ubiquitination by the SCF $\beta$-TrCP1 complex (Wan et al. 2004) as well as the RING-domain protein Ectodermin under conditions of protein overexpression (Dupont et al. 2005).

In addition to the role of polyubiquitin as a tag for degradation via the $26 \mathrm{~S}$ proteasome, it is now becoming clear that the addition of one or a few ubiquitin molecules can act as a signal much like phosphorylation. Recent work pointed to this kind of regulation of Smad2 activity by Itch (Bai et al. 2004). Itch is a ubiquitin ligase involved in the immune response of $\mathrm{T}$ lymphocytes and has a similar domain structure to the Smurfs, suggesting it may also regulate TGF $\beta$ family signals. Although Itchnull mice are viable, embryonic fibroblasts lacking Itch were less sensitive to TGF $\beta$-induced growth inhibition (Bai et al. 2004). Itch was shown to promote Smad2 ubiquitination but did not result in significant Smad2 degradation. Rather, it was proposed that ubiquitinated Smad2 interacted better with the TGF $\beta$ receptor complex, resulting in enhanced TGF $\beta$ signaling (Bai et al. 2004). Itch did appear to promote polyubiquitination, and so it is not clear how Smad2 polyubiquitinated by Itch differs from Smad2 polyubiquitinated by Smurf2.

The I-Smads are both targets for ubiquitination and cofactors that promote receptor ubiquitination. Smad7 can be targeted for ubiquitination by the RING-domain E3 ligase, Arkadia (Koinuma et al. 2003). The resulting removal of inhibitory Smad7 results in increased responses to both TGF $\beta$ and BMP, which fits with the original identification of Arkadia as an enhancer of Nodal-related signaling required for node formation during mouse embryogenesis (Episkopou et al. 2001) and mesoderm induction in Xenopus (Niederlander et al. 
2001). Thus, degradation of the inhibitor amplifies the signal. The interplay of Smurfs and the I-Smads is, however, more complex. The susceptibility to ubiquitination may be controlled by acetylation of the same lysine residue. Nuclear Smad7 can be acetylated by p300 at two $\mathrm{N}$-terminal lysines, which are also the sites of ubiquitin attachment (Gronroos et al. 2002). Acetylation prevented receptor-induced ubiquitination of $\operatorname{Smad} 7$ by Smurf without affecting the subcellular distribution of Smad7, raising the possibility that acetylated Smad7 is competent to exit the nucleus and inhibit receptor activity (Gronroos et al. 2002).

\section{Regulation of Smads by sumoylation}

The rising interest in the ubiquitin-like modification involving SUMO (small ubiquitin-like modifier) has shown that sumoylation alters protein function by creating a composite interaction domain (Song et al. 2004). One of the outcomes of sumoylation is the modulation of protein targeting within the cell (Johnson 2004). There is now growing evidence for a role for sumoylation in modulating numerous transcriptional responses, often leading to decreased transcriptional activity. Several recent reports have demonstrated the sumoylation of Smad4. Two sumoylation consensus motifs $(\psi \mathrm{K} x \mathrm{E}$, where $\psi$ is hydrophobic, $x$ is variable and $\mathrm{K}$ is the lysine to be modified [Melchior 2000]) are present in Smad4, one in the MH1 domain, and one in the linker region, and these are the sites of Smad4 sumoylation (Lee et al. 2003; Lin et al. 2003a,b; Ohshima and Shimotohno 2003).

Two opposite effects of sumoylation on Smad4 activity have been reported: increased (Lee et al. 2003; Lin et al. 2003a,b; Ohshima and Shimotohno 2003; Liang et al. 2004) and decreased transcriptional activity (Long et al. 2004; Chang et al. 2005). It is possible that the differences observed are due to the use of different cell lines or different readouts of Smad function. However, the apparent contradiction may reflect the more general complexities of the effects of protein sumoylation. In another transcription factor (Elk-1), it has been shown that SUMO can recruit the histone deacetylase, HDAC2, resulting in repression of genes that would normally be activated (Yang and Sharrocks 2004). A recent report proposes a similar mechanism for regulation of Smad4 by sumoylation, by binding of the factor Daxx (Chang et al. 2005).

A different explanation is required for the observation that sumoylation increases Smad4 activity. This may come from a potential competition between ubiquitination and sumoylation of the same lysines on Smad4. In a different protein, IкB, sumoylation on the same lysines that are also targets of ubiquitination protects against IкB ubiquitination and degradation (Desterro et al. 1998). There is evidence that mutation of the two SUMO target lysines in Smad4 increased its half-life, with a concomitant decrease in the level of ubiquitinated Smad4 (Lin et al. 2003a). It is, therefore, possible that an activated Smad complex can be either sumoylated or ubiquiti- nated on the same two lysines in Smad4. If ubiquitinated, it will be targeted to the proteasome and Smadinduced gene expression will be decreased. In contrast, sumoylation would block ubiquitination and prolong the half-life of the complex, allowing it to reach a target gene. Sumoylation may be a relatively dynamic modification. Thus, it may be that SUMO plays roles in activation and repression and that the balance between ubiquitination, sumoylation, and desumoylation is critical.

Several groups identified members of the PIAS (protein inhibitor of activated STAT) family as SUMO E3 ligases for Smad4 (Fig. 5; Lee et al. 2003; Ohshima and Shimotohno 2003; Liang et al. 2004). PIAS proteins are SUMO E3s for a growing number of proteins involved in transcriptional regulation, but it also appears that in some cases they act as transcriptional cofactors independent of their ability to promote sumoylation (Schmidt and Muller 2003). As is the case for many SUMO-modified proteins, a clear understanding of the important physiological outcomes requires further investigation.

\section{Smads as nodes for signal integration}

Cytokines of the TGF $\beta$ family control many critical processes during development and tissue homeostasis. Cell proliferation, differentiation, positioning, migration, metabolism, and apoptosis are exquisitely regulated and coordinated by Smad signaling pathways. However, this occurs in concert with other pathways impinging on the cell. The correct integration of these inputs is essential for their proper interpretation by the cell in the control of gene expression. Smad proteins provide an important platform for the integration of many inputs. At one level or another, essentially all major signaling pathways have been shown to converge on Smads as a node for signal integration. Here we discuss only a few prominent examples (Fig. 6).

\section{Elements for integration: the linker, the corridor, and the partners}

Besides the receptor-mediated phosphorylation of the Cterminal tail, three main venues exist for Smad regulation by diverse inputs. One venue is the linker region between the MH1 and MH2 domains of RSmads, which undergoes phosphorylation by pathways that activate ERK MAP kinases, CDKs, and other protein kinases, as well as recognition by Smurf ubiquitin ligases. In Smad4, the linker region is a site for sumoylation and for presentation or occlusion of the NES.

Another important venue for signal integration is provided by the various surfaces of the Smad molecule that contact DNA-binding cofactors, coactivators, or corepressors. The most remarkable of these surfaces is the hydrophobic corridor on the $\mathrm{MH} 2$ domain. This region is a site for competing interactions with the cytoplasmic anchor SARA, nucleoporins, and specific DNA-binding proteins involved in recruitment of Smads to DNA. Inputs that alter the levels of these different proteins may 


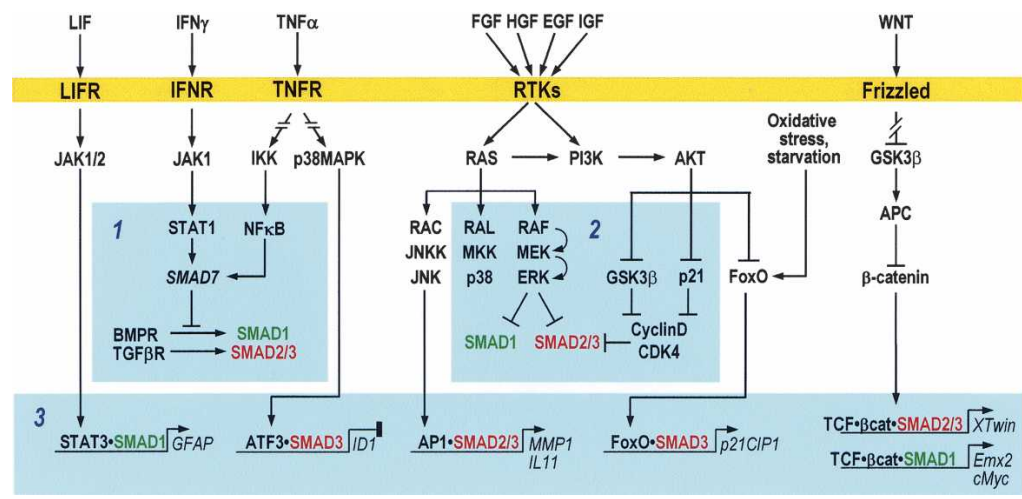

Figure 6. Smads as nodes for signal integration. The scheme depicts some examples of cross-talk between Smads and major signal transduction pathways. Inputs by other pathways occur by signal-mediated expression of Smad7, which acts as an inhibitor of receptor-mediated Smad activation (box 1); signal-mediated phosphorylation of the Smad linker region, which negatively regulates certain Smad functions (box 2); and signal-mediated activation of transcription factors that target specific genes in concert with Smads (box 3). (RTKs) Receptor tyrosine kinases. See the text for other abbreviations and details. For additional details on signaling steps, see Massagué (2004) and references therein. influence the competitive advantage of one Smad partner over others for binding into the hydrophobic corridor.

A third major venue for input integration are the DNA-binding cofactors, coactivators, and corepressors themselves, which are subject to their own set of regulatory inputs that secondarily affect the activity of Smad transcriptional complexes in which these factors participate (Fig. 6). Collectively, these three venues convey inputs from essentially all the major signal transduction pathways.

\section{Smad cross-talk with major pathways}

Ras and TGF $\beta$ pathways act cooperatively as well as antagonistically during development and in oncogenesis (Massagué 2003). In response to mitogenic signals via receptor tyrosine kinases and the Ras/MAP kinase pathway, Smad1, Smad2, and Smad3 are phosphorylated by ERK at multiple MAP kinase sites in the linker region that negatively affect Smad function (Kretzschmar et al. 1997). The integration of Smad and Ras/MAPK pathways during Xenopus development has provided insights into the relevance of this regulatory node. In Xenopus development, BMP signaling via Smad1 inhibits neural development, and this effect is blocked by ERK-activating factors FGF8 and IGF2 (Wilson et al. 1997; Pera et al. 2003). These inputs inhibit Smad function and favor neural differentiation and mesoderm dorsalization in Xenopus by inhibiting BMP signaling (Pera et al. 2003). Ectopic expression of Smad1 in developing Xenopus embryos led to a mild ventralization phenotype, which was strongly enhanced when a Smad1 mutant lacking all MAP kinase sites was used. In various neural induction assays, this Smad1 mutant blocked the neuralizing effects of FGF8 and IGF2, whereas the wild-type Smad1 did not. FGF8 and IGF2 induce MAPK-dependent phosphorylation of Smad1 at the linker region in cell culture (Pera et al. 2003), as do EGF and HGF (Kretzschmar et al. 1997). Furthermore, Smad1 can undergo linker phosphorylation by endogenous MAPK in Xenopus embryos (Pera et al. 2003). The onset of Smad1 linker phosphorylation occurs in the early to mid-gastrula stage, along with an increase in endogenous Erk activation.
Experiments with targeted mouse mutations demonstrated that phosphorylation of Smad1 by MAP kinases and BMP receptors have qualitatively different outcomes, not just effects on the magnitude of the BMP signal (Aubin et al. 2004). A mutant Smad1 lacking the C-terminal phosphorylation sites had largely the same phenotype as the null mutation. In contrast, mutations that abolished MAP kinase phosphorylation sites generated novel phenotypes affecting germ cells and gastric function, suggesting that these phosphorylations may not only limit the action of BMP, but also modulate it in a more subtle manner.

In Xenopus, the mid-gastrula-stage ectoderm abruptly loses competence to generate mesoderm in response to activin-like signals (Grainger and Gurdon 1989). This coincides with an inability of Smad2 to translocate to the nucleus in response to activin and an increase in Smad2 phosphorylation (Grimm and Gurdon 2002). Remarkably, a mutant Smad2 lacking MAPK sites in the linker was able to translocate into the nucleus in response to activin at the gastrula stage, suggesting that the loss of competence in the ectoderm is mediated by linker phosphorylation and nuclear exclusion of Smad2 (Grimm and Gurdon 2002). How phosphorylation of the linker region may inhibit nuclear accumulation or alter other functions of RSmads remains an enigma.

The p38 and JNK pathways can selectively modulate certain TGF $\beta$ gene responses that depend on transcription factors controlled by p38 and JNK MAP kinases. One example of this regulation is provided by the inhibitory effect of TGF $\beta$ on Id1 expression in epithelial cells (Chen et al. 2001). TGF $\beta$ inhibits Id1 expression through Smad3-Smad4 in concert with ATF3. ATF3 itself can be induced by the activity of JNK and p38. TNF $\alpha$ (tumor necrosis factor $\alpha$ ) and other agonists that signal via JNK and p38 induce ATF3 expression, which favors the repression of Id1 by TGF $\beta$-activated Smads (Kang et al. 2003).

The PI3K-AKT pathway inhibits TGF $\beta$ gene responses that depend on FoxO factors. AKT phosphorylates FoxO factors, causing their exclusion from the nucleus (Brunet et al. 1999). As a result, high levels of AKT activity inhibit the ability of FoxO to function as a partner of Smad3-Smad4 complexes for p21Cip1 induction /Seoane 
et al. 2004). Mitogenic growth factors that activate the PI3K-AKT pathway can thereby attenuate the induction of $p 21$ Cip 1 by TGF $\beta$ and counteract its anti-mitogenic activity. Hyperactivation of the PI3K-AKT pathway by loss of the tumor suppressor lipid phosphatase PTEN, as commonly occurs in glioblastoma cells, can have a similar effect (Seoane et al. 2004).

The Wnt/ $\beta$-catenin/TCF pathway cooperates with TGF $\beta$ signaling by forming Smad-TCF complexes that control joint target genes. Smad4 has been shown to interact with $\beta$-catenin and TCF/LEF1, which form a transcriptional activation complex in response to Wnt signaling. This complex activates Xtwn expression during Xenopus development (Nishita et al. 2000). Similarly, in mouse development, Wnt and BMP signaling cooperatively regulate expression of Emx2 (Theil et al. 2002). In an animal model of renal dysplasia, an interaction between $\beta$-catenin and a Smad1-Smad4 complex cooperatively regulates $c-M y c$ expression $(\mathrm{Hu}$ and Rosenblum 2005).

Several forms of cooperation between Smads and nuclear receptors have been proposed. Interactions of the androgen receptor (AR) and Smad3 have been reported, which result in enhancement or inhibition of AR activity by Smad3 and repression of TGF $\beta$ signaling by AR, depending on the conditions (Hayes et al. 2001; Chipuk et al. 2002; Kang et al. 2002).

Other forms of cross-talk affect Smads less directly. Interferon- $\gamma$ signaling via the Jak/STAT1 pathway (Ulloa et al. 1999) and TNF $\alpha$ signaling via NF-кB (Bitzer et al. 2000) can induce the expression of Smad7. This accumulation of Smad7 in interferon- $\gamma$ or $\mathrm{TNF} \alpha$-treated cells inhibits TGF $\beta$ receptor signaling. IFN $\gamma$ signaling via the inflammatory response pathway is generally antagonistic to TGF $\beta$ signals, and up-regulation of $\operatorname{Smad} 7 \mathrm{ex}-$ pression by IFN $\gamma$ provides a mechanistic basis for this antagonism. However, the interplay between Smad and STAT or TNF $\alpha$ pathways is not purely antagonistic. Recall that Smad1 and STAT3 cooperatively activate the glial fibrillary acidic protein to induce astrocyte differentiation (Nakashima et al. 1999), and TNF $\alpha$ can cooperate with TGF $\beta$ in the repression of Id1 expression (Kang et al. 2003). There are many other examples in which Smads interact with other signal-regulated transcription factors, either directly or via coactivators.

\section{Perspectives}

The extraordinary amount of information accumulated in just a few years has shed substantial light on the molecular properties that make the Smad proteins such widespread and versatile nodes for signal integration and regulation of gene expression. This versatility is a result of the remarkable functional flexibility of these proteins. The MH1 domain, the linker region, and, very especially, the MH2 domain, with their interactive surfaces that admit many different partners and regulatory inputs, convert a simple pathway into a major highway for cell signaling. These considerations take us back to biological problems. Building on a large body of information and new high-throughput technologies, a new era has started for the field at large, in which long-standing problems of major importance, but daunting complexity, can be addressed at last. To this end, the field is likely to move in several complementary directions:

- Long-standing questions about the basic elements of this pathway, such as the basis for Smad-dependent signaling in the absence of Smad4, the role of the MH1 domain insert, or the identity of RSmad phosphatases, still need to be addressed.

- The structural basis for the assembly of Smad transcriptional complexes on the DNA is not known. Yet, insights into this question would be critical for understanding the versatility of Smad proteins and providing information for selectively targeting Smad interactions that lead to fibrotic disorders or tumor metastasis.

- The transcriptional action of Smad complexes has yet to be parsed into discrete steps of sequential recruitment or cyclical exchange of chromatin remodeling activities that give rise to temporally restricted transcriptional responses.

- The functional consequences of several Smad posttranslation modifications (e.g., linker phosphorylation, sumoylation) remain largely unknown. One challenge is to determine the role of these modifications in physiological settings.

- The effects of TGF $\beta$ on specific target genes and the cellular functions that these genes control have been studied largely one at a time. The ability to dissect Smad-regulated gene synexpression groups should help define how diverse cellular functions are jointly controlled by TGF $\beta-S m a d$ signals. This would shed light into how TGF $\beta$-induced changes in cell cycle progression, for example, are orchestrated with changes in cytokine production, cell adhesion behavior, or cell shape.

- Current high-throughput methods for the analysis of protein interactions are taking the modeling of signal transduction processes to an entirely new level. However, when this level of resolution is achieved, the information that it yields is useful to the extent that it relates to physiologically meaningful conditions. Challenges in this area include the need to perform these analyses under such conditions.

Admittedly, the list of future directions could be much longer, and the choices listed above may just reflect the particular interests of the authors. However, it is clear that the TGF $\beta$ signal transduction pathway, and the Smad transcription factors that have been studied so doggedly for years, have come of age. This important piece of molecular machinery controlling the complex behavior of metazoan cells remains a major focus of study, not only to further define its own workings, but also as a tool to pry open many aspects of fundamental biology, as well as the pathogenesis of human diseases resulting from the malfunction of the Smad pathways. 


\section{Acknowledgments}

We thank the members of our laboratories for many fruitful discussions on the topics covered in this article. Work in the laboratory of J.M. is supported by NIH grant CA34610 and by HHMI, in the laboratory of J.S. by the Spanish Ministry of Health grant FIS(PI040766), and in the laboratory of D.W. by grants from the NIH (HD39926) and from the March of Dimes (6-FY04-77). We thank Yigong Shi for help with illustrations of crystal structures.

\section{References}

Afrakhte, M., Moren, A., Jossan, S., Itoh, S., Sampath, K., Westermark, B., Heldin, C.H., Heldin, N.E., and ten Dijke, P. 1998. Induction of inhibitory Smad6 and Smad7 mRNA by TGF- $\beta$ family members. Biochem. Biophys. Res. Commun. 249: 505-511.

Akiyoshi, S., Inoue, H., Hanai, J., Kusanagi, K., Nemoto, N., Miyazono, K., and Kawabata, M. 1999. c-Ski acts as a transcriptional co-repressor in transforming growth factor- $\beta$ signaling through interaction with Smads. J. Biol. Chem. 274: 35269-35277.

Alliston, T., Choy, L., Ducy, P., Karsenty, G., and Derynck, R. 2001. TGF- $\beta$-induced repression of CBFA1 by Smad 3 decreases cbfal and osteocalcin expression and inhibits osteoblast differentiation. EMBO J. 20: 2254-2272.

Attisano, L. and Wrana, J.L. 2002. Signal transduction by the TGF- $\beta$ superfamily. Science 296: 1646-1647.

Aubin, J., Davy, A., and Soriano, P. 2004. In vivo convergence of BMP and MAPK signaling pathways: Impact of differential Smad1 phosphorylation on development and homeostasis. Genes \& Dev. 18: 1482-1494.

Bai, S., Shi, X., Yang, X., and Cao, X. 2000. Smad6 as a transcriptional corepressor. J. Biol. Chem. 275: 8267-8270.

Bai, R.Y., Koester, C., Ouyang, T., Hahn, S.A., Hammerschmidt, M., Peschel, C., and Duyster, J. 2002. SMIF, a Smad4-interacting protein that functions as a co-activator in TGF $\beta$ signalling. Nat. Cell Biol. 4: 181-190.

Bai, Y., Yang, C., Hu, K., Elly, C., and Liu, Y.C. 2004. Itch E3 ligase-mediated regulation of TGF- $\beta$ signaling by modulating smad2 phosphorylation. Mol. Cell 15: 825-831.

Baldessari, D., Shin, Y., Krebs, O., Konig, R., Koide, T., Vinayagam, A., Fenger, U., Mochii, M., Terasaka, C., Kitayama, A., et al. 2005. Global gene expression profiling and cluster analysis in Xenopus laevis. Mech. Dev. 122: 441-475.

Bannister, A.J. and Kouzarides, T. 1996. The CBP co-activator is a histone acetyltransferase. Nature 384: 641-643.

Bayliss, R., Littlewood, T., and Stewart, M. 2000. Structural basis for the interaction between FxFG nucleoporin repeats and importin- $\beta$ in nuclear trafficking. Cell 102: 99-108.

Benchabane, H. and Wrana, J.L. 2003. GATA- and Smad1-dependent enhancers in the Smad7 gene differentially interpret bone morphogenetic protein concentrations. Mol. Cell. Biol. 23: 6646-6661.

Berk, M., Desai, S.Y., Heyman, H.C., and Colmenares, C. 1997. Mice lacking the ski proto-oncogene have defects in neurulation, craniofacial, patterning, and skeletal muscle development. Genes \& Dev. 11: 2029-2039.

Bhushan, A., Chen, Y., and Vale, W. 1998. Smad7 inhibits mesoderm formation and promotes neural cell fate in Xenopus embryos. Dev. Biol. 200: 260-268.

Bitzer, M., von Gersdorff, G., Liang, D., Dominguez-Rosales, A., Beg, A.A., Rojkind, M., and Bottinger, E.P. 2000. A mechanism of suppression of TGF- $\beta / S M A D$ signaling by NF-кB/ RelA. Genes \& Dev. 14: 187-197.
Bonni, S., Wang, H.R., Causing, C.G., Kavsak, P., Stroschein, S.L., Luo, K., and Wrana, J.L. 2001. TGF- $\beta$ induces assembly of a Smad2-Smurf2 ubiquitin ligase complex that targets SnoN for degradation. Nat. Cell Biol. 3: 587-595.

Bourillot, P.Y., Garrett, N., and Gurdon, J.B. 2002. A changing morphogen gradient is interpreted by continuous transduction flow. Development 129: 2167-2180.

Brodin, G., Ahgren, A., ten Dijke, P., Heldin, C.H., and Heuchel, R. 2000. Efficient TGF- $\beta$ induction of the Smad7 gene requires cooperation between AP-1, Sp1, and Smad proteins on the mouse Smad7 promoter. J. Biol. Chem. 275: 2902329030.

Brown III, C.O., Chi, X., Garcia-Gras, E., Shirai, M., Feng, X.H., and Schwartz, R.J. 2004. The cardiac determination factor, Nkx2-5, is activated by mutual cofactors GATA-4 and Smad1/4 via a novel upstream enhancer. J. Biol. Chem. 279: 10659-10669.

Brummel, T., Abdollah, S., Haerry, T.E., Shimell, M.J., Merriam, J., Raftery, L., Wrana, J.L., and O'Connor, M.B. 1999. The Drosophila activin receptor baboon signals through $\mathrm{dSmad} 2$ and controls cell proliferation but not patterning during larval development. Genes \& Dev. 13: 98-111.

Brunet, A., Bonni, A., Zigmond, M.J., Lin, M.Z., Juo, P., Hu, L.S., Anderson, M.J., Arden, K.C., Blenis, J., and Greenberg, M.E. 1999. Akt promotes cell survival by phosphorylating and inhibiting a Forkhead transcription factor. Cell 96: 857868.

Casellas, R. and Brivanlou, A.H. 1998. Xenopus Smad7 inhibits both the activin and BMP pathways and acts as a neural inducer. Dev. Biol. 198: 1-12.

Chacko, B.M., Qin, B., Correia, J.J., Lam, S.S., de Caestecker, M.P., and Lin, K. 2001. The L3 loop and C-terminal phosphorylation jointly define Smad protein trimerization. Nat. Struct. Biol. 8: 248-253.

Chacko, B.M., Qin, B.Y., Tiwari, A., Shi, G., Lam, S., Hayward, L.J., De Caestecker, M., and Lin, K. 2004. Structural basis of heteromeric smad protein assembly in TGF- $\beta$ signaling. Mol. Cell 15: 813-823.

Chai, J., Wu, J.W., Yan, N., Massagué, J., Pavletich, N.P., and Shi, Y. 2003. Features of a Smad3 MH1-DNA complex. Roles of water and zinc in DNA binding. J. Biol. Chem. 278: 20327-20331.

Chang, C.C., Lin, D.Y., Fang, H.I., Chen, R.H., and Shih, H.M. 2005. Daxx mediates the small ubiquitin-like modifier-dependent transcriptional repression of Smad4. J. Biol. Chem. 280: 10164-10173.

Chen, X., Rubock, M.J., and Whitman, M. 1996. A transcriptional partner for MAD proteins in TGF- $\beta$ signalling. Nature 383: 691-696.

Chen, X., Weisberg, E., Fridmacher, V., Watanabe, M., Naco, G., and Whitman, M. 1997. Smad4 and FAST-1 in the assembly of activin-responsive factor. Nature 389: 85-89.

Chen, Y.G., Liu, F., and Massagué, J. 1997. Mechanism of TGF $\beta$ receptor inhibition by FKBP12. EMBO J. 16: 3866-3876.

Chen, C.R., Kang, Y., and Massagué, J. 2001. Defective repression of c-myc in breast cancer cells: A loss at the core of the transforming growth factor $\beta$ growth arrest program. Proc. Natl. Acad. Sci. 98: 992-1009.

Chen, C.R., Kang, Y., Siegel, P.M., and Massagué, J. 2002. E2F4/5 and p107 as Smad cofactors linking the TGF $\beta$ receptor to c-myc repression. Cell 110: 19-32.

Chipuk, J.E., Cornelius, S.C., Pultz, N.J., Jorgensen, J.S., Bonham, M.J., Kim, S.J., and Danielpour, D. 2002. The androgen receptor represses transforming growth factor- $\beta$ signaling through interaction with Smad3. J. Biol. Chem. 277: 12401248 . 
Chu, G.C., Dunn, N.R., Anderson, D.C., Oxburgh, L., and Robertson, E.J. 2004. Differential requirements for Smad4 in TGF $\beta$-dependent patterning of the early mouse embryo. Development 131: 3501-3512.

Colmenares, C., Sutrave, P., Hughes, S.H., and Stavnezer, E. 1991. Activation of the c-ski oncogene by overexpression. J. Virol. 65: 4929-4935.

Colmenares, C., Heilstedt, H.A., Shaffer, L.G., Schwartz, S., Berk, M., Murray, J.C., and Stavnezer, E. 2002. Loss of the SKI proto-oncogene in individuals affected with $1 \mathrm{p} 36$ deletion syndrome is predicted by strain-dependent defects in Ski-/- mice. Nat. Genet. 30: 106-109.

Cordenonsi, M., Dupont, S., Maretto, S., Insinga, A., Imbriano, C., and Piccolo, S. 2003. Links between tumor suppressors: p53 is required for TGF- $\beta$ gene responses by cooperating with Smads. Cell 113: 301-314.

Das, P., Maduzia, L.L., and Padgett, R.W. 1999. Genetic approaches to TGF 3 signaling pathways. Cytokine Growth Factor Rev. 10: 179-186.

Datta, P.K., Chytil, A., Gorska, A.E., and Moses, H.L. 1998. Identification of STRAP, a novel WD domain protein in transforming growth factor- $\beta$ signaling. J. Biol. Chem. 273: 34671-34674.

de Caestecker, M.P., Yahata, T., Wang, D., Parks, W.T., Huang, S., Hill, C.S., Shioda, T., Roberts, A.B., and Lechleider, R.J. 2000. The Smad4 activation domain (SAD) is a proline-rich, p300-dependent transcriptional activation domain. J. Biol. Chem. 275: 2115-2122.

Denissova, N.G., Pouponnot, C., Long, J., He, D., and Liu, F. 2000. Transforming growth factor $\beta$-inducible independent binding of SMAD to the Smad7 promoter. Proc. Natl. Acad. Sci. 97: 6397-6402.

Derynck, R. and Zhang, Y.E. 2003. Smad-dependent and Smadindependent pathways in TGF- $\beta$ family signalling. Nature 425: 577-584.

Derynck, R., Akhurst, R.J., and Balmain, A. 2001. TGF- $\beta$ signaling in tumor suppression and cancer progression. Nat. Genet. 29: 117-129.

Desterro, J.M., Rodriguez, M.S., and Hay, R.T. 1998. SUMO-1 modification of IкB $\alpha$ inhibits NF-кB activation. Mol. Cell 2: 233-239.

Di Guglielmo, G.M., Le Roy, C., Goodfellow, A.F., and Wrana, J.L. 2003. Distinct endocytic pathways regulate TGF- $\beta$ receptor signalling and turnover. Nat. Cell Biol. 5: 410421.

Dunn, N.R., Koonce, C.H., Anderson, D.C., Islam, A., Bikoff, E.K., and Robertson, E.J. 2005. Mice exclusively expressing the short isoform of Smad2 develop normally and are viable and fertile. Genes \& Dev. 19: 152-163.

Dupont, S., Zacchigna, L., Cordenonsi, M., Soligo, S., Adorno, M., Rugge, M., and Piccolo, S. 2005. Germ-layer specification and control of cell growth by Ectodermin, a Smad4 ubiquitin ligase. Cell 121: 87-99.

Dyson, S. and Gurdon, J.B. 1998. The interpretation of position in a morphogen gradient as revealed by occupancy of activin receptors. Cell 93: 557-568.

Episkopou, V., Arkell, R., Timmons, P.M., Walsh, J.J., Andrew, R.L., and Swan, D. 2001. Induction of the mammalian node requires Arkadia function in the extraembryonic lineages. Nature 410: 825-830.

Fahrenkrog, B. and Aebi, U. 2003. The nuclear pore complex: Nucleocytoplasmic transport and beyond. Nat. Rev. Mol. Cell Biol. 4: 757-766.

Felici, A., Wurthner, J.U., Parks, W.T., Giam, L.R., Reiss, M., Karpova, T.S., McNally, J.G., and Roberts, A.B. 2003. TLP, a novel modulator of TGF- $\beta$ signaling, has opposite effects on
Smad2- and Smad3-dependent signaling. EMBO J. 22: 44654477.

Feng, X.-H., Zhang, Y., Wu, R.-Y., and Derynck, R. 1998. The tumor suppressor Smad4/DPC4 and transcriptional adaptor $\mathrm{CBP} / \mathrm{p} 300$ are coactivators for $\mathrm{Smad} 3$ in TGF- $\beta$-induced transcriptional activation. Genes \& Dev. 12: 2153-2163.

Feng, X.H., Lin, X., and Derynck, R. 2000. Smad2, Smad3 and Smad4 cooperate with Sp1 to induce p15(Ink4B) transcription in response to TGF- $\beta$. EMBO J. 19: 5178-5193.

Foletta, V.C., Lim, M.A., Soosairajah, J., Kelly, A.P., Stanley, E.G., Shannon, M., He, W., Das, S., Massagué, J., and Bernard, O. 2003. Direct signaling by the BMP type II receptor via the cytoskeletal regulator LIMK1. J. Cell Biol. 162: 10891099.

Fornerod, M., Ohno, M., Yoshida, M., and Mattaj, I.Q. 1997. CRM1 is an export receptor for leucine-rich nuclear export signals. Cell 90: 1051-1060.

Frederick, J.P., Liberati, N.R., Waddell, D.S., Shi, Y., and Wang, X.F. 2004. Transforming growth factor $\beta$-mediated transcriptional repression of $\mathrm{c}-\mathrm{myc}$ is dependent on direct binding of Smad3 to a novel repressive Smad binding element. Mol. Cell. Biol. 24: 2546-2559.

Fukuchi, M., Imamura, T., Chiba, T., Ebisawa, T., Kawabata, M., Tanaka, K., and Miyazono, K. 2001. Ligand-dependent degradation of Smad3 by a ubiquitin ligase complex of ROC1 and associated proteins. Mol. Biol. Cell 12: 1431-1443.

Furuhashi, M., Yagi, K., Yamamoto, H., Furukawa, Y., Shimada, S., Nakamura, Y., Kikuchi, A., Miyazono, K., and Kato, M. 2001. Axin facilitates Smad3 activation in the transforming growth factor $\beta$ signaling pathway. Mol. Cell. Biol. 21: 5132 5141.

Galvin, K.M., Donovan, M.J., Lynch, C.A., Meyer, R.I., Paul, R.J., Lorenz, J.N., Fairchild-Huntress, V., Dixon, K.L., Dunmore, J.H., Gimbrone Jr., M.A., et al. 2000. A role for smad6 in development and homeostasis of the cardiovascular system. Nat. Genet. 24: 171-174.

Gawantka, V., Pollet, N., Delius, H., Vingron, M., Pfister, R., Nitsch, R., Blumenstock, C., and Niehrs, C. 1998. Gene expression screening in Xenopus identifies molecular pathways, predicts gene function and provides a global view of embryonic patterning. Mech. Dev. 77: 95-141.

Germain, S., Howell, M., Esslemont, G.M., and Hill, C.S. 2000. Homeodomain and winged-helix transcription factors recruit activated Smads to distinct promoter elements via a common Smad interaction motif. Genes \& Dev. 14: 435451 .

Gorlich, D. and Kutay, U. 1999. Transport between the cell nucleus and the cytoplasm. Annu. Rev. Cell Dev. Biol. 15: 607-660.

Grainger, R.M. and Gurdon, J.B. 1989. Loss of competence in amphibian induction can take place in single nondividing cells. Proc. Nat1. Acad. Sci. 86: 1900-1904.

Grimm, O.H. and Gurdon, J.B. 2002. Nuclear exclusion of Smad2 is a mechanism leading to loss of competence. Nat. Cell Biol. 4: 519-522.

Gripp, K.W., Wotton, D., Edwards, M.C., Roessler, E., Ades, L., Meinecke, P., Richieri-Costa, A., Zackai, E.H., Massagué, J., Muenke, M., et al. 2000. Mutations in TGIF cause holoprosencephaly and link NODAL signalling to human neural axis determination. Nat. Genet. 25: 205-208.

Gronroos, E., Hellman, U., Heldin, C.H., and Ericsson, J. 2002. Control of Smad7 stability by competition between acetylation and ubiquitination. Mol. Cell 10: 483-493.

Hanai, J., Chen, L.F., Kanno, T., Ohtani-Fujita, N., Kim, W.Y., Guo, W.H., Imamura, T., Ishidou, Y., Fukuchi, M., Shi, M.J., et al. 1999. Interaction and functional cooperation of PEBP2/ 
CBF with Smads. Synergistic induction of the immunoglobulin germline C $\alpha$ promoter. J. Biol. Chem. 274: 3157731582.

Hata, A., Lo, R.S., Wotton, D., Lagna, G., and Massagué, J. 1997. Mutations increasing autoinhibition inactivate tumour suppressors Smad2 and Smad4. Nature 388: 82-87.

Hata, A., Lagna, G., Massagué, J., and Hemmati-Brivanlou, A. 1998. Smad6 inhibits BMP/Smad1 signaling by specifically competing with the Smad4 tumor suppressor. Genes \& Dev. 12: 186-197.

Hata, A., Seoane, J., Lagna, G., Montalvo, E., Hemmati-Brivanlou, A., and Massagué, J. 2000. OAZ uses distinct DNA- and protein-binding zinc fingers in separate BMP-Smad and Olf signaling pathways. Cell 100: 229-240.

Hayashi, H., Abdollah, S., Qiu, Y., Cai, J., Xu, Y.Y., Grinnell, B.W., Richardson, M.A., Topper, J.N., Gimbrone, M.A., Wrana, J.L., et al. 1997. The MAD-related protein Smad7 associates with the TGF $\beta$ receptor and functions as an antagonist of TGF $\beta$ signaling. Cell 89: 1165-1173.

Hayes, S.A., Zarnegar, M., Sharma, M., Yang, F., Peehl, D.M., ten Dijke, P., and Sun, Z. 2001. SMAD3 represses androgen receptor-mediated transcription. Cancer Res. 61: 21122118.

Hayhurst, M. and McConnell, S.K. 2003. Mouse models of holoprosencephaly. Curr. Opin. Neurol. 16: 135-141.

He, J., Tegen, S.B., Krawitz, A.R., Martin, G.S., and Luo, K. 2003. The transforming activity of Ski and SnoN is dependent on their ability to repress the activity of Smad proteins. J. Biol. Chem. 278: 30540-30547.

Hellemans, J., Preobrazhenska, O., Willaert, A., Debeer, P., Verdonk, P.C., Costa, T., Janssens, K., Menten, B., Van Roy, N., Vermeulen, S.J., et al. 2004. Loss-of-function mutations in LEMD3 result in osteopoikilosis, Buschke-Ollendorff syndrome and melorheostosis. Nat. Genet. 36: 1213-1218.

Heyer, J., Escalante-Alcalde, D., Lia, M., Boettinger, E., Edelmann, W., Stewart, C.L., and Kucherlapati, R. 1999. Postgastrulation Smad2-deficient embryos show defects in embryo turning and anterior morphogenesis. Proc. Natl. Acad. Sci. 96: $12595-12600$.

Hocevar, B.A., Smine, A., Xu, X.X., and Howe, P.H. 2001. The adaptor molecule Disabled-2 links the transforming growth factor $\beta$ receptors to the Smad pathway. EMBO J. 20: 27892801.

Hogan, B.L. 1996. Bone morphogenetic proteins: Multifunctional regulators of vertebrate development. Genes \& Dev. 10: $1580-1594$

Hoodless, P.A., Haerry, T., Abdollah, S., Stapleton, M., O'Connor, M.B., Attisano, L., and Wrana, J.L. 1996. MADR1, a MAD-related protein that functions in BMP2 signalling pathways. Cell 85: 489-500.

$\mathrm{Hu}$, M.C. and Rosenblum, N.D. 2005. Smad1, $\beta$-catenin and Tcf4 associate in a molecular complex with the Myc promoter in dysplastic renal tissue and cooperate to control Myc transcription. Development 132: 215-225.

Hua, X., Miller, Z.A., Benchabane, H., Wrana, J.L., and Lodish, H.F. 2000. Synergism between transcription factors TFE3 and Smad3 in transforming growth factor- $\beta$-induced transcription of the Smad7 gene. I. Biol. Chem. 275: 33205-33208.

Huse, M., Chen, Y.G., Massagué, J., and Kuriyan, J. 1999. Crystal structure of the cytoplasmic domain of the type I TGF $\beta$ receptor in complex with FKBP12. Cell 96: 425-436.

Huse, M., Muir, T.W., Xu, L., Chen, Y.G., Kuriyan, J., and Massagué, J. 2001. The TGF $\beta$ receptor activation process: An inhibitor- to substrate-binding switch. Mol. Cell 8: 671-682.

Hyman, C.A., Bartholin, L., Newfeld, S.J., and Wotton, D. 2003.
Drosophila TGIF proteins are transcriptional activators. Mol. Cell. Biol. 23: 9262-9274.

Iavarone, A. and Massagué, J. 1997. Repression of the CDK activator Cdc25A and cell-cycle arrest by cytokine TGF- $\beta$ in cells lacking the CDK inhibitor p15. Nature 387: 417-422.

1999. E2F and histone deacetylase mediate transforming growth factor $\beta$ repression of cdc25A during keratinocyte cell cycle arrest. Mol. Cell. Biol. 19: 916-922.

Imamura, T., Takase, M., Nishihara, A., Oeda, E., Hanai, J., Kawabata, M., and Miyazono, K. 1997. Smad6 inhibits signalling by the TGF- $\beta$ superfamily. Nature 389: 622-626.

Imoto, I., Pimkhaokham, A., Watanabe, T., Saito-Ohara, F., Soeda, E., and Inazawa, J. 2000. Amplification and overexpression of TGIF2, a novel homeobox gene of the TALE superclass, in ovarian cancer cell lines. Biochem. Biophys. Res. Commun. 276: 264-270.

Inman, G.J. and Hill, C.S. 2002. Stoichiometry of active smadtranscription factor complexes on DNA. J. Biol. Chem. 277: 51008-51016.

Inman, G.J., Nicolas, F.J., and Hill, C.S. 2002. Nucleocytoplasmic shuttling of Smads 2, 3, and 4 permits sensing of TGF- $\beta$ receptor activity. Mol. Cell 10: 283-294.

Ishida, W., Hamamoto, T., Kusanagi, K., Yagi, K., Kawabata, M., Takehara, K., Sampath, T.K., Kato, M., and Miyazono, K. 2000. Smad6 is a Smad1/5-induced smad inhibitor. Characterization of bone morphogenetic protein-responsive element in the mouse Smad6 promoter. I. Biol. Chem. 275: 6075-6079.

Ishisaki, A., Yamato, K., Nakao, A., Nonaka, K., Ohguchi, M., ten Dijke, P., and Nishihara, T. 1998. Smad7 is an activininducible inhibitor of activin-induced growth arrest and apoptosis in mouse B cells. J. Biol. Chem. 273: 24293-24296.

Itoh, S., Landstrom, M., Hermansson, A., Itoh, F., Heldin, C.H., Heldin, N.E., and ten Dijke, P. 1998. Transforming growth factor $\beta 1$ induces nuclear export of inhibitory Smad7. J. Biol. Chem. 273: 29195-29201.

Itoh, S., Ericsson, J., Nishikawa, J., Heldin, C.H., and ten Dijke, P. 2000. The transcriptional co-activator $\mathrm{P} / \mathrm{CAF}$ potentiates TGF- $\beta /$ Smad signaling. Nucleic Acids Res. 28: 42914298.

Izutsu, K., Kurokawa, M., Imai, Y., Maki, K., Mitani, K., and Hirai, H. 2001. The corepressor CtBP interacts with Evi-1 to repress transforming growth factor $\beta$ signaling. Blood 97: 2815-2822.

Izzi, L. and Attisano, L. 2004. Regulation of the TGF $\beta$ signalling pathway by ubiquitin-mediated degradation. Oncogene 23: 2071-2078.

Jans, D.A., Xiao, C.Y., and Lam, M.H. 2000. Nuclear targeting signal recognition: A key control point in nuclear transport? Bioessays 22: 532-544.

Jayaraman, L. and Massagué, J. 2000. Distinct oligomeric states of SMAD proteins in the transforming growth factor- $\beta$ pathway. J. Biol. Chem. 275: 40710-40717.

Johnson, E.S. 2004. Protein modification by SUMO. Annu. Rev. Biochem. 73: 355-382.

Kadakia, M., Brown, T.L., McGorry, M.M., and Berberich, S.J. 2002. MdmX inhibits Smad transactivation. Oncogene 21: $8776-8785$

Kang, H.Y., Huang, K.E., Chang, S.Y., Ma, W.L., Lin, W.J., and Chang, C. 2002. Differential modulation of androgen receptor-mediated transactivation by Smad3 and tumor suppressor Smad4. J. Biol. Chem. 277: 43749-43756.

Kang, Y., Chen, C.R., and Massagué, J. 2003. A self-enabling TGF $\beta$ response coupled to stress signaling: Smad engages stress response factor ATF3 for Id1 repression in epithelial cells. Mol. Cell 11: 915-926. 
Kang, J.S., Alliston, T., Delston, R., and Derynck, R. 2005. Repression of Runx 2 function by TGF- $\beta$ through recruitment of class II histone deacetylases by Smad3. EMBO J. 24: 25432555.

Kang, Y., He, W., Tulley, S., Gupta, G.P., Serganova, I., Chen, C.-R., Manova-Todorova, K., Blasberg, R., Gerald, W.L., and Massagué, J. 2005. Breast cancer bone metastasis mediated by the Smad tumor suppressor pathway. Proc. Natl. Acad. Sci. 102: 13909-13914.

Karaulanov, E., Knochel, W., and Niehrs, C. 2004. Transcriptional regulation of BMP4 synexpression in transgenic Xenopus. EMBO J. 23: 844-856.

Kato, Y., Habas, R., Katsuyama, Y., Naar, A.M., and He, X. 2002. A component of the ARC/Mediator complex required for TGF $\beta /$ Nodal signalling. Nature 418: 641-646.

Kavsak, P., Rasmussen, R.K., Causing, C.G., Bonni, S., Zhu, H., Thomsen, G.H., and Wrana, J.L. 2000. Smad7 binds to Smurf2 to form an E3 ubiquitin ligase that targets the TGF $\beta$ receptor for degradation. Mol. Cell 6: 1365-1375.

Kim, D.W. and Lassar, A.B. 2003. Smad-dependent recruitment of a histone deacetylase/Sin3A complex modulates the bone morphogenetic protein-dependent transcriptional repressor activity of Nkx3.2. Mol. Cell. Biol. 23: 8704-8717.

Kim, J., Johnson, K., Chen, H.J., Carroll, S., and Laughon, A. 1997. Drosophila Mad binds to DNA and directly mediates activation of vestigial by Decapentaplegic. Nature 388: 304308.

Kim, R.H., Wang, D., Tsang, M., Martin, J., Huff, C., de Caestecker, M.P., Parks, W.T., Meng, X., Lechleider, R.J., Wang, T., et al. 2000. A novel smad nuclear interacting protein, SNIP1, suppresses p300-dependent TGF- $\beta$ signal transduction. Genes \& Dev. 14: 1605-1616.

Kirkpatrick, H., Johnson, K., and Laughon, A. 2001. Repression of dpp targets by binding of brinker to mad sites. J. Biol. Chem. 276: 18216-18222.

Koinuma, D., Shinozaki, M., Komuro, A., Goto, K., Saitoh, M., Hanyu, A., Ebina, A., Nukiwa, T., Miyazawa, K., Imamura, T., et al. 2003. Arkadia amplifies TGF- $\beta$ superfamily signalling through degradation of Smad7. EMBO J. 22: 64586470.

Korchynskyi, O. and ten Dijke, P. 2002. Identification and functional characterization of distinct critically important bone morphogenetic protein-specific response elements in the Id1 promoter. J. Biol. Chem. 277: 4883-4891.

Kretzschmar, M., Doody, J., and Massagué, J. 1997. Opposing BMP and EGF signalling pathway converge on the TGF $\beta$ family mediator Smad1. Nature 389: 618-622.

Kretzschmar, M., Doody, J., Timokhina, I., and Massagué, J. 1999. A mechanism of repression of TGF- $\beta /$ Smad signaling by oncogenic Ras. Genes \& Dev. 13: 804-816.

Kurisaki, A., Kose, S., Yoneda, Y., Heldin, C.H., and Moustakas, A. 2001. Transforming growth factor- $\beta$ induces nuclear import of Smad3 in an importin- $\beta 1$ and Ran-dependent manner. Mol. Biol. Cell 12: 1079-1091.

Kurokawa, M., Mitani, K., Irie, K., Matsuyama, T., Takahashi, T., Chiba, S., Yazaki, Y., Matsumoto, K., and Hirai, H. 1998. The oncoprotein Evi-1 represses TGF $\beta$ signalling by inhibiting Smad3. Nature 394: 92-96.

Lee, P.S., Chang, C., Liu, D., and Derynck, R. 2003. Sumoylation of Smad4, the common Smad mediator of transforming growth factor- $\beta$ family signaling. J. Biol. Chem. 278: 2785327863.

Letterio, J.J. and Roberts, A.B. 1998. Regulation of immune responses by TGF- $\beta$. Annu. Rev. Immunol. 16: 137-161.

Liang, M., Melchior, F., Feng, X.H., and Lin, X. 2004. Regulation of Smad4 Sumoylation and transforming growth factor- $\beta$ sig- naling by protein inhibitor of activated STAT1. I. Biol. Chem. 279: 22857-22865.

Lien, C.L., McAnally, J., Richardson, J.A., and Olson, E.N. 2002. Cardiac-specific activity of an Nkx2-5 enhancer requires an evolutionarily conserved Smad binding site. Dev. Biol. 244: 257-266.

Lin, X., Liang, M., Liang, Y.Y., Brunicardi, F.C., and Feng, X.H. 2003a. SUMO-1/Ubc9 promotes nuclear accumulation and metabolic stability of tumor suppressor Smad4. I. Biol. Chem. 278: 31043-31048.

Lin, X., Liang, M., Liang, Y.Y., Brunicardi, F.C., Melchior, F., and Feng, X.H. 2003b. Activation of transforming growth factor- $\beta$ signaling by SUMO-1 modification of tumor suppressor Smad4/DPC4. J. Biol. Chem. 278: 18714-18719.

Lin, X., Liang, Y.Y., Sun, B., Liang, M., Shi, Y., Brunicardi, F.C., and Feng, X.H. 2003c. Smad6 recruits transcription corepressor $\mathrm{CtBP}$ to repress bone morphogenetic protein-induced transcription. Mol. Cell. Biol. 23: 9081-9093.

Lin, H.K., Bergmann, S., and Pandolfi, P.P. 2004. Cytoplasmic PML function in TGF- $\beta$ signalling. Nature 431: 205-211.

Liu, F., Hata, A., Baker, J.C., Doody, J., Carcamo, J., Harland, R.M., and Massagué, J. 1996. A human Mad protein acting as a BMP-regulated transcriptional activator. Nature 381: 620 623.

Liu, F., Pouponnot, C., and Massagué, J. 1997. Dual role of the Smad4/DPC4 tumor suppressor in TGF $\beta$-inducible transcriptional complexes. Genes \& Dev. 11: 3157-3167.

Liu, D., Black, B.L., and Derynck, R. 2001. TGF- $\beta$ inhibits muscle differentiation through functional repression of myogenic transcription factors by Smad3. Genes \& Dev. 15: 2950-2966.

Liu, D., Kang, J.S., and Derynck, R. 2004. TGF- $\beta$-activated Smad3 represses MEF2-dependent transcription in myogenic differentiation. $E M B O$ J. 23: 1557-1566.

Lo, R.S. and Massagué, J. 1999. Ubiquitin-dependent degradation of TGF- $\beta$-activated Smad2. Nat. Cell Biol. 1: 472 478.

Long, J., Wang, G., He, D., and Liu, F. 2004. Repression of Smad4 transcriptional activity by SUMO modification. Biochem. J. 379: 23-29.

Lopez-Rovira, T., Chalaux, E., Massagué, J., Rosa, J.L., and Ventura, F. 2002. Direct binding of Smadl and Smad4 to two distinct motifs mediates bone morphogenetic protein-specific transcriptional activation of Id1 gene. J. Biol. Chem. 277: 3176-3185.

Lopingco, M.C. and Perkins, A.S. 1996. Molecular analysis of Evil, a zinc finger oncogene involved in myeloid leukemia. Curr. Top. Microbiol. Immunol. 211: 211-222.

Luo, K., Stroschein, S.L., Wang, W., Chen, D., Martens, E., Zhou, S., and Zhou, Q. 1999. The Ski oncoprotein interacts with the Smad proteins to repress TGF $\beta$ signaling. Genes \& Dev. 13: 2196-2206.

Macias-Silva, M., Hoodless, P.A., Tang, S.J., Buchwald, M., and Wrana, J.L. 1998. Specific activation of Smad1 signaling pathways by the BMP7 type I receptor, ALK2. J. Biol. Chem. 273: 25628-25636.

Marquez, R.M., Singer, M.A., Takaesu, N.T., Waldrip, W.R., Kraytsberg, Y., and Newfeld, S.J. 2001. Transgenic analysis of the Smad family of TGF- $\beta$ signal transducers in Drosophila melanogaster suggests new roles and new interactions between family members. Genetics 157: 1639-1648.

Marty, T., Muller, B., Basler, K., and Affolter, M. 2000. Schnurri mediates Dpp-dependent repression of brinker transcription. Nat. Cell Biol. 2: 745-749.

Massagué, J. 1998. TGF $\beta$ signal transduction. Annu. Rev. Biochem. 67: 753-791. 
2003. Integration of Smad and MAPK pathways: A link and a linker revisited. Genes \& Dev. 17: 2993-2997.

- 2004. G1 cell-cycle control and cancer. Nature 432: 298-306.

Massagué, J. and Chen, Y.G. 2000. Controlling TGF- $\beta$ signaling. Genes \& Dev. 14: 627-644.

Massagué, J. and Wotton, D. 2000. Transcriptional control by the TGF- $\beta /$ Smad signaling system. EMBO J. 19: 1745-1754.

Massagué, J., Blain, S.W., and Lo, R.S. 2000. TGF $\beta$ signaling in growth control, cancer, and heritable disorders. Cell 103: 295-309.

Matsuura, I., Denissova, N.G., Wang, G., He, D., Long, J., and Liu, F. 2004. Cyclin-dependent kinases regulate the antiproliferative function of Smads. Nature 430: 226-231.

Mattaj, I.W. and Englmeier, L. 1998. Nucleocytoplasmic transport: The soluble phase. Annu. Rev. Biochem. 67: 265-306.

Melchior, F. 2000. SUMO-Nonclassical ubiquitin. Annu. Rev. Cell. Dev. Biol. 16: 591-626.

Melhuish, T.A. and Wotton, D. 2000. The interaction of the carboxyl terminus-binding protein with the Smad corepressor TGIF is disrupted by a holoprosencephaly mutation in TGIF. J. Biol. Chem. 275: 39762-39766.

Melhuish, T.A., Gallo, C.M., and Wotton, D. 2001. TGIF2 interacts with histone deacetylase 1 and represses transcription. J. Biol. Chem. 276: 32109-32114.

Miura, S., Takeshita, T., Asao, H., Kimura, Y., Murata, K., Sasaki, Y., Hanai, J.L., Beppu, H., Tsukazaki, T., Wrana, J.L., et al. 2000. Hgs (Hrs), a FYVE domain protein, is involved in Smad signaling through cooperation with SARA. Mol. Cell. Biol. 20: 9346-9355.

Moren, A., Imamura, T., Miyazono, K., Heldin, C.H., and Moustakas, A. 2005. Degradation of the tumor suppressor Smad4 by WW and HECT domain ubiquitin ligases. J. Biol. Chem. 280: 22115-22123.

Muller, B., Hartmann, B., Pyrowolakis, G., Affolter, M., and Basler, K. 2003. Conversion of an extracellular Dpp/BMP morphogen gradient into an inverse transcriptional gradient. Cell 113: 221-233.

Murakami, G., Watabe, T., Takaoka, K., Miyazono, K., and Imamura, T. 2003. Cooperative inhibition of bone morphogenetic protein signaling by Smurf1 and inhibitory Smads. Mol. Biol. Cell 14: 2809-2817.

Nakakuki, K., Imoto, I., Pimkhaokham, A., Fukuda, Y., Shimada, Y., Imamura, M., Amagasa, T., and Inazawa, J. 2002. Novel targets for the $18 \mathrm{p} 11.3$ amplification frequently observed in esophageal squamous cell carcinomas. Carcinogenesis 23: 19-24.

Nakao, A., Afrakhte, M., Morén, A., Nakayama, T., Christian, J.L., Heuchel, R., Itoh, S., Kawabata, M., Heldin, N.E., Heldin, C.H., et al. 1997. Identification of Smad7, a TGF $\beta$-inducible antagonist of TGF- $\beta$ signaling. Nature 389: 631-635.

Nakashima, K., Yanagisawa, M., Arakawa, H., Kimura, N., Hisatsune, T., Kawabata, M., Miyazono, K., and Taga, T. 1999. Synergistic signaling in fetal brain by STAT3-Smad1 complex bridged by p300. Science 284: 479-482.

Niederlander, C., Walsh, J.J., Episkopou, V., and Jones, C.M. 2001. Arkadia enhances nodal-related signalling to induce mesendoderm. Nature 410: 830-834.

Niehrs, C. and Meinhardt, H. 2002. Modular feedback. Nature 417: 35-36.

Niehrs, C. and Pollet, N. 1999. Synexpression groups in eukaryotes. Nature 402: 483-487.

Nishita, M., Hashimoto, M.K., Ogata, S., Laurent, M.N., Ueno, N., Shibuya, H., and Cho, K.W. 2000. Interaction between Wnt and TGF- $\beta$ signalling pathways during formation of Spemann's organizer. Nature 403: 781-785.
Nomura, T., Khan, M.M., Kaul, S.C., Dong, H.D., Wadhwa, R., Colmenares, C., Kohno, I., and Ishii, S. 1999. Ski is a component of the histone deacetylase complex required for transcriptional repression by Mad and thyroid hormone receptor. Genes \& Dev. 13: 412-423.

Ogryzko, V.V., Schiltz, R.L., Russanova, V., Howard, B.H., and Nakatani, Y. 1996. The transcriptional coactivators p300 and CBP are histone acetyltransferases. Cell 87: 953-959.

Ohshima, T. and Shimotohno, K. 2003. Transforming growth factor- $\beta$-mediated signaling via the p38 MAP kinase pathway activates Smad-dependent transcription through SUMO-1 modification of Smad4. J. Biol. Chem. 278: 5083350842.

Onichtchouk, D., Chen, Y.G., Dosch, R., Gawantka, V., Delius, H., Massagué, J., and Niehrs, C. 1999. Silencing of TGF- $\beta$ signalling by the pseudoreceptor BAMBI. Nature 401: 480485.

Oshima, M., Oshima, H., and Taketo, M.M. 1996. TGF- $\beta$ receptor type II deficiency results in defects of yolk sac hematopoiesis and vasculogenesis. Dev. Biol. 179: 297-302.

Ozdamar, B., Bose, R., Barrios-Rodiles, M., Wang, H.R., Zhang, Y., and Wrana, J.L. 2005. Regulation of the polarity protein Par6 by TGF $\beta$ receptors controls epithelial cell plasticity. Science 307: 1603-1609.

Pan, D., Estevez-Salmeron, L.D., Stroschein, S.L., Zhu, X., He, J., Zhou, S., and Luo, K. 2005. The integral inner nuclear membrane protein MAN1 physically interacts with the RSmad proteins to repress signaling by the transforming growth factor- $\beta$ superfamily of cytokines. J. Biol. Chem. 280: 15992-16001.

Pardali, E., Xie, X.Q., Tsapogas, P., Itoh, S., Arvanitidis, K., Heldin, C.H., ten Dijke, P., Grundstrom, T., and Sideras, P. 2000. Smad and AML proteins synergistically confer transforming growth factor $\beta 1$ responsiveness to human germline IgA genes. J. Biol. Chem. 275: 3552-3560.

Pardali, K., Kurisaki, A., Moren, A., ten Dijke, P., Kardassis, D., and Moustakas, A. 2000. Role of Smad proteins and transcription factor $\mathrm{Sp} 1$ in $\mathrm{p} 21$ (Waf1/Cip1) regulation by transforming growth factor- $\beta$. J. Biol. Chem. 275: 29244-29256.

Pera, E.M., Ikeda, A., Eivers, E., and De Robertis, E.M. 2003. Integration of IGF, FGF, and anti-BMP signals via Smad1 phosphorylation in neural induction. Genes \& Dev. 17: 3023-3028.

Pierreux, C.E., Nicolas, F.J., and Hill, C.S. 2000. Transforming growth factor $\beta$-independent shuttling of Smad4 between the cytoplasm and nucleus. Mol. Cell. Biol. 20: 9041-9054.

Podos, S.D., Hanson, K.K., Wang, Y.C., and Ferguson, E.L. 2001. The DSmurf ubiquitin-protein ligase restricts BMP signaling spatially and temporally during Drosophila embryogenesis. Dev. Cell 1: 567-578.

Pouponnot, C., Jayaraman, L., and Massagué, J. 1998. Physical and functional interactions of Smads and p300/CBP. J. Biol. Chem. 273: 22865-22868.

Qin, B.Y., Chacko, B.M., Lam, S.S., de Caestecker, M.P., Correia, J.J., and Lin, K. 2001. Structural basis of Smad1 activation by receptor kinase phosphorylation. Mol. Cell 8: 1303 1312.

Raftery, L.A. and Sutherland, D.J. 1999. TGF- $\beta$ family signal transduction in Drosophila development: From Mad to Smads. Dev. Biol. 210: 251-268.

Randall, R.A., Germain, S., Inman, G.J., Bates, P.A., and Hill, C.S. 2002. Different Smad2 partners bind a common hydrophobic pocket in Smad2 via a defined proline-rich motif. EMBO T. 21: 145-156.

Rout, M.P., Aitchison, J.D., Suprapto, A., Hjertaas, K., Zhao, Y., and Chait, B.T. 2000. The yeast nuclear pore complex: Com- 
position, architecture, and transport mechanism. I. Cell Biol. 148: 635-651.

Rushlow, C., Colosimo, P.F., Lin, M.C., Xu, M., and Kirov, N. 2001. Transcriptional regulation of the Drosophila gene zen by competing Smad and Brinker inputs. Genes \& Dev. 15: 340-351.

Schier, A.F. 2003. Nodal signaling in vertebrate development. Annu. Rev. Cell Dev. Biol. 19: 589-621.

Schmidt, D. and Muller, S. 2003. PIAS/SUMO: New partners in transcriptional regulation. Cell. Mol. Life Sci. 60:25612574.

Seo, S.R., Lallemand, F., Ferrand, N., Pessah, M., L'Hoste, S., Camonis, J., and Atfi, A. 2004. The novel E3 ubiquitin ligase Tiull associates with TGIF to target Smad2 for degradation. EMBO J. 23: 3780-3792.

Seoane, J., Pouponnot, C., Staller, P., Schader, M., Eilers, M., and Massagué, J. 2001. TGF $\beta$ influences Myc, Miz-1 and Smad to control the CDK inhibitor p15INK4b. Nat. Cell Biol. 3: 400408.

Seoane, J., Le, H.V., and Massagué, J. 2002. Myc suppression of the p21(Cip1) Cdk inhibitor influences the outcome of the p53 response to DNA damage. Nature 419: 729-734.

Seoane, J., Le, H.V., Shen, L., Anderson, S.A., and Massagué, J. 2004. Integration of Smad and forkhead pathways in the control of neuroepithelial and glioblastoma cell proliferation. Cell 117: 211-223.

Shen, X., Hu, P.P., Liberati, N.T., Datto, M.B., Frederick, J.P., and Wang, X.F. 1998. TGF- $\beta$-induced phosphorylation of Smad3 regulates its interaction with coactivator p300/ CREB-binding protein. Mol. Biol. Cell 9: 3309-3319.

Shi, Y. and Massagué, J. 2003. Mechanisms of TGF- $\beta$ signaling from cell membrane to the nucleus. Cell 113: 685-700.

Shi, Y., Hata, A., Lo, R.S., Massagué, J., and Pavletich, N.P. 1997. A structural basis for mutational inactivation of the tumour suppressor Smad4. Nature 388: 87-93.

Shi, Y., Wang, Y.F., Jayaraman, L., Yang, H., Massagué, J., and Pavletich, N.P. 1998. Crystal structure of a Smad MH1 domain bound to DNA: Insights on DNA binding in TGF- $\beta$ signaling. Cell 94: 585-594.

Shim, S., Bae, N., and Han, J.K. 2002. Bone morphogenetic protein-4-induced activation of Xretpos is mediated by Smads and Olf-1/EBF associated zinc finger (OAZ). Nucleic Acids Res. 30: 3107-3117.

Shimizu, K., Bourillot, P.Y., Nielsen, S.J., Zorn, A.M., and Gurdon, J.B. 2001. Swift is a novel BRCT domain coactivator of Smad2 in transforming growth factor $\beta$ signaling. Mol. Cell. Biol. 21: 3901-3912.

Shioda, T., Lechleider, R.J., Dunwoodie, S.L., Li, H., Yahata, T., de Caestecker, M.P., Fenner, M.H., Roberts, A.B., and Isselbacher, K.J. 1998. Transcriptional activating activity of Smad4: Roles of SMAD hetero-oligomerization and enhancement by an associating transactivator. Proc. Natl. Acad. Sci. 95: 9785-9790.

Siegel, P.M. and Massagué, J. 2003. Cytostatic and apoptotic actions of TGF- $\beta$ in homeostasis and cancer. Nat. Rev. Cancer 3: 807-821.

Siegel, P.M., Shu, W., and Massagué, J. 2003. Mad upregulation and Id2 repression accompany transforming growth factor (TGF)- $\beta$-mediated epithelial cell growth suppression. J. Biol. Chem. 278: 35444-35450.

Sirard, C., de la Pompa, J.L., Elia, A., Itie, A., Mirtsos, C., Cheung, A., Hahn, S., Wakeham, A., Schwartz, L., Kern, S.E., et al. 1998. The tumor suppressor gene Smad4/Dpc4 is required for gastrulation and later for anterior development of the mouse embryo. Genes \& Dev. 12: 107-119.

Song, J., Durrin, L.K., Wilkinson, T.A., Krontiris, T.G., and
Chen, Y. 2004. Identification of a SUMO-binding motif that recognizes SUMO-modified proteins. Proc. Natl. Acad. Sci. 101: 14373-14378.

Souchelnytskyi, S., Nakayama, T., Nakao, A., Moren, A., Heldin, C.H., Christian, J.L., and ten Dijke, P. 1998. Physical and functional interaction of murine and Xenopus Smad7 with bone morphogenetic protein receptors and transforming growth factor- $\beta$ receptors. J. Biol. Chem. 273: 25364 25370.

Staller, P., Peukert, K., Kiermaier, A., Seoane, J., Lukas, J., Karsunky, H., Moroy, T., Bartek, J., Massagué, J., Hanel, F., et al. 2001. Repression of p15INK4b expression by Myc through association with Miz-1. Nat. Cell Biol. 3: 392-399.

Stavnezer, E., Barkas, A.E., Brennan, L.A., Brodeur, D., and Li, Y. 1986. Transforming Sloan-Kettering viruses generated from the cloned v-ski oncogene by in vitro and in vivo recombinations. J. Virol. 57: 1073-1083.

Stopa, M., Anhuf, D., Terstegen, L., Gatsios, P., Gressner, A.M., and Dooley, S. 2000. Participation of Smad2, Smad3, and Smad4 in transforming growth factor $\beta$ (TGF- $\beta$ )-induced activation of Smad7. THE TGF- $\beta$ response element of the promoter requires functional Smad binding element and E-box sequences for transcriptional regulation. I. Biol. Chem. 275: 29308-29317.

Stroschein, S.L., Wang, W., Zhou, S., Zhou, Q., and Luo, K. 1999. Negative feedback regulation of TGF- $\beta$ signaling by the SnoN oncoprotein. Science 286: 771-774.

Stroschein, S.L., Bonni, S., Wrana, J.L., and Luo, K. 2001. Smad3 recruits the anaphase-promoting complex for ubiquitination and degradation of SnoN. Genes \& Dev. 15: 28222836.

Subramanian, G., Schwarz, R.E., Higgins, L., McEnroe, G., Chakravarty, S., Dugar, S., and Reiss, M. 2004. Targeting endogenous transforming growth factor $\beta$ receptor signaling in SMAD4-deficient human pancreatic carcinoma cells inhibits their invasive phenotype1. Cancer Res. 64: 52005211.

Sun, Y., Liu, X., Eaton, E.N., Lane, W.S., Lodish, H.F., and Weinberg, R.A. 1999a. Interaction of the Ski oncoprotein with Smad3 regulates TGF- $\beta$ signaling. Mol. Cell 4: 499-509.

Sun, Y., Liu, X., Ng-Eaton, E., Lodish, H.F., and Weinberg, R.A. 1999b. SnoN and ski protooncoproteins are rapidly degraded in response to transforming growth factor $\beta$ signaling. Proc. Natl. Acad. Sci. 96: 12442-12447.

Sun, Y., Nadal-Vicens, M., Misono, S., Lin, M.Z., Zubiaga, A., Hua, X., Fan, G., and Greenberg, M.E. 2001. Neurogenin promotes neurogenesis and inhibits glial differentiation by independent mechanisms. Cell 104: 365-376.

Suzuki, C., Murakami, G., Fukuchi, M., Shimanuki, T., Shikauchi, Y., Imamura, T., and Miyazono, K. 2002. Smurf1 regulates the inhibitory activity of Smad7 by targeting Smad7 to the plasma membrane. J. Biol. Chem. 277: 39919-39925.

Tajima, Y., Goto, K., Yoshida, M., Shinomiya, K., Sekimoto, T., Yoneda, Y., Miyazono, K., and Imamura, T. 2003. Chromosomal region maintenance 1 (CRM1)-dependent nuclear export of Smad ubiquitin regulatory factor 1 (Smurf1) is essential for negative regulation of transforming growth factor- $\beta$ signaling by Smad7. J. Biol. Chem. 278: 10716-10721.

Takeda, M., Mizuide, M., Oka, M., Watabe, T., Inoue, H., Suzuki, H., Fujita, T., Imamura, T., Miyazono, K., and Miyazawa, K. 2004. Interaction with Smad4 is indispensable for suppression of BMP signaling by c-Ski. Mol. Biol. Cell 15: 963-972.

Tang, S.J., Hoodless, P.A., Lu, Z., Breitman, M.L., McInnes, R.R., Wrana, J.L., and Buchwald, M. 1998. The Tlx-2 homeobox gene is a downstream target of BMP signalling and is 
required for mouse mesoderm development. Development 125: $1877-1887$.

Tang, Y., Katuri, V., Dillner, A., Mishra, B., Deng, C.X., and Mishra, L. 2003. Disruption of transforming growth factor- $\beta$ signaling in ELF $\beta$-spectrin-deficient mice. Science 299: 574 577.

Theil, T., Aydin, S., Koch, S., Grotewold, L., and Ruther, U. 2002. Wnt and Bmp signalling cooperatively regulate graded Emx2 expression in the dorsal telencephalon. Development 129: 3045-3054.

Topper, J.N., DiChiara, M.R., Brown, J.D., Williams, A.J., Falb, D., Collins, T., and Gimbrone Jr., M.A. 1998. CREB binding protein is a required coactivator for Smad-dependent, transforming growth factor $\beta$ transcriptional responses in endothelial cells. Proc. Nat1. Acad. Sci. 95: 9506-9511.

Tsang, M., Friesel, R., Kudoh, T., and Dawid, I.B. 2002. Identification of Sef, a novel modulator of FGF signalling. Nat. Cell Biol. 4: 165-169.

Tsukazaki, T., Chiang, T.A., Davison, A.F., Attisano, L., and Wrana, J.L. 1998. SARA, a FYVE domain protein that recruits Smad2 to the TGFß receptor. Cell 95: 779-791.

Tsuneizumi, K., Nakayama, T., Kamoshida, Y., Kornberg, T.B., Christian, J.L., and Tabata, T. 1997. Daughters against dpp modulates dpp organizing activity in Drosophila wing development. Nature 389: 627-631.

Ulloa, L., Doody, J., and Massagué, J. 1999. Inhibition of transforming growth factor- $\beta / S M A D$ signalling by the interferon$\gamma /$ STAT pathway. Nature 397: 710-713.

Vega, R.B., Matsuda, K., Oh, J., Barbosa, A.C., Yang, X., Meadows, E., McAnally, J., Pomajzl, C., Shelton, J.M., Richardson, J.A., et al. 2004. Histone deacetylase 4 controls chondrocyte hypertrophy during skeletogenesis. Cell 119: 555-566.

von Gersdorff, G., Susztak, K., Rezvani, F., Bitzer, M., Liang, D., and Bottinger, E.P. 2000. Smad3 and Smad4 mediate transcriptional activation of the human Smad7 promoter by transforming growth factor $\beta$. J. Biol. Chem. 275: 1132011326.

Waldrip, W.R., Bikoff, E.K., Hoodless, P.A., Wrana, J.L., and Robertson, E.J. 1998. Smad2 signaling in extraembryonic tissues determines anterior-posterior polarity of the early mouse embryo. Cell 92: 797-808.

Wan, M., Tang, Y., Tytler, E.M., Lu, C., Jin, B., Vickers, S.M., Yang, L., Shi, X., and Cao, X. 2004. Smad4 protein stability is regulated by ubiquitin ligase SCF $\beta$-TrCP1. J. Biol. Chem. 279: $14484-14487$.

Wang, Z.G., Delva, L., Gaboli, M., Rivi, R., Giorgio, M., CordonCardo, C., Grosveld, F., and Pandolfi, P.P. 1998. Role of PML in cell growth and the retinoic acid pathway. Science 279: $1547-1551$.

Wang, W., Mariani, F.V., Harland, R.M., and Luo, K. 2000. Ski represses bone morphogenic protein signaling in Xenopus and mammalian cells. Proc. Natl. Acad. Sci. 97: 1439414399.

Watanabe, M., Masuyama, N., Fukuda, M., and Nishida, E. 2000. Regulation of intracellular dynamics of Smad4 by its leucine-rich nuclear export signal. EMBO Rep. 1: 176-182.

Whitehurst, A.W., Wilsbacher, J.L., You, Y., Luby-Phelps, K., Moore, M.S., and Cobb, M.H. 2002. ERK2 enters the nucleus by a carrier-independent mechanism. Proc. Natl. Acad. Sci. 99: 7496-7501.

Whitman, M. 1998. Smads and early developmental signaling by the TGF $\beta$ superfamily. Genes \& Dev. 12: 2445-2462.

Wicks, S.J., Lui, S., Abdel-Wahab, N., Mason, R.M., and Chantry, A. 2000. Inactivation of smad-transforming growth factor $\beta$ signaling by $\mathrm{Ca}(2+)$-calmodulin-dependent protein kinase II. Mol. Cell. Biol. 20: 8103-8111.
Wilson, P.A., Lagna, G., Suzuki, A., and Hemmati-Brivanlou, A. 1997. Concentration-dependent patterning of the Xenopus ectoderm by BMP4 and its signal transducer Smad1. Development 124: 3177-3184.

Wisotzkey, R.G., Mehra, A., Sutherland, D.J., Dobens, L.L., Liu, X., Dohrmann, C., Attisano, L., and Raftery, L.A. 1998. Medea is a Drosophila Smad4 homolog that is differentially required to potentiate DPP responses. Development 125: 1433-1445.

Wong, C., Rougier-Chapman, E.M., Frederick, J.P., Datto, M.B., Liberati, N.T., Li, J.M., and Wang, X.F. 1999. Smad3-Smad4 and AP-1 complexes synergize in transcriptional activation of the c-Jun promoter by transforming growth factor $\beta$. Mol. Cell. Biol. 19: 1821-1830.

Wotton, D., Lo, R.S., Lee, S., and Massagué, J. 1999a. A Smad transcriptional corepressor. Cell 97: 29-39.

Wotton, D., Lo, R.S., Swaby, L.A., and Massagué, J. 1999b. Multiple modes of repression by the Smad transcriptional corepressor TGIF. J. Biol. Chem. 274: 37105-37110.

Wrana, J.L., Attisano, L., Wieser, R., Ventura, F., and Massagué, J. 1994. Mechanism of activation of the TGF- $\beta$ receptor. $\mathrm{Na}$ ture 370: 341-347.

Wu, G., Chen, Y.G., Ozdamar, B., Gyuricza, C.A., Chong, P.A., Wrana, J.L., Massagué, J., and Shi, Y. 2000. Structural basis of Smad2 recognition by the Smad anchor for receptor activation. Science 287: 92-97.

Wu, J.W., Fairman, R., Penry, J., and Shi, Y. 2001a. Formation of a stable heterodimer between Smad2 and Smad4. J. Biol. Chem. 276: 20688-20694.

Wu, J.W., Hu, M., Chai, J., Seoane, J., Huse, M., Li, C., Rigotti, D.J., Kyin, S., Muir, T.W., Fairman, R., et al. 2001b. Crystal structure of a phosphorylated Smad2. Recognition of phosphoserine by the MH2 domain and insights on Smad function in TGF- $\beta$ signaling. Mol. Cell 8: 1277-1289.

Wu, J.W., Krawitz, A.R., Chai, J., Li, W., Zhang, F., Luo, K., and Shi, Y. 2002. Structural mechanism of Smad4 recognition by the nuclear oncoprotein Ski: Insights on Ski-mediated repression of TGF- $\beta$ signaling. Cell 111: 357-367.

Wurthner, J.U., Frank, D.B., Felici, A., Green, H.M., Cao, Z., Schneider, M.D., McNally, J.G., Lechleider, R.J., and Roberts, A.B. 2001. Transforming growth factor- $\beta$ receptor-associated protein 1 is a Smad4 chaperone. J. Biol. Chem. 276: 19495-19502.

Xiao, Z., Liu, X., and Lodish, H.F. 2000. Importin $\beta$ mediates nuclear translocation of Smad 3. J. Biol. Chem. 275: 2342523428.

Xiao, C., Shim, J.M., Kluppel, M., Zhang, S.S., Dong, C., Flavell, R.A., Fu, X.Y., Wrana, J.L., Hogan, B.L., and Ghosh, S. 2003. Ecsit is required for Bmp signaling and mesoderm formation during mouse embryogenesis. Genes \& Dev. 17: 2933-2949.

$\mathrm{Xu}, \mathrm{L}$. and Massagué, J. 2004. Nucleocytoplasmic shuttling of signal transducers. Nat. Rev. Mol. Cell Biol. 5: 209-219.

$\mathrm{Xu}, \mathrm{X}$., Yin, Z., Hudson, J.B., Ferguson, E.L., and Frasch, M. 1998. Smad proteins act in combination with synergistic and antagonistic regulators to target Dpp responses to the Drosophila mesoderm. Genes \& Dev. 12: 2354-2370.

Xu, L., Chen, Y.G., and Massagué, J. 2000. The nuclear import function of Smad2 is masked by SARA and unmasked by TGF $\beta$-dependent phosphorylation. Nat. Cell Biol. 2: 559562.

Xu, L., Kang, Y., Col, S., and Massagué, J. 2002. Smad2 nucleocytoplasmic shuttling by nucleoporins CAN/Nup214 and Nup153 feeds TGF $\beta$ signaling complexes in the cytoplasm and nucleus. Mol. Cell 10: 271-282.

Xu, L., Alarcon, C., Col, S., and Massagué, J. 2003. Distinct domain utilization by Smad3 and Smad4 for nucleoporin in- 
Massagué et al.

teraction and nuclear import. J. Biol. Chem. 278: 4256942577.

Yagi, K., Goto, D., Hamamoto, T., Takenoshita, S., Kato, M., and Miyazono, K. 1999. Alternatively spliced variant of Smad2 lacking exon 3. Comparison with wild-type Smad2 and Smad3. J. Biol. Chem. 274: 703-709.

Yahata, T., de Caestecker, M.P., Lechleider, R.J., Andriole, S., Roberts, A.B., Isselbacher, K.J., and Shioda, T. 2000. The MSG1 non-DNA-binding transactivator binds to the p300/ CBP coactivators, enhancing their functional link to the Smad transcription factors. J. Biol. Chem. 275: 8825-8834.

Yamakawa, N., Tsuchida, K., and Sugino, H. 2002. The rasGAPbinding protein, Dok-1, mediates activin signaling via serine/threonine kinase receptors. EMBO J. 21: 1684-1694.

Yang, S.H. and Sharrocks, A.D. 2004. SUMO promotes HDACmediated transcriptional repression. Mol. Cell 13: 611-617.

Yokoya, F., Imamoto, N., Tachibana, T., and Yoneda, Y. 1999. $\beta$-Catenin can be transported into the nucleus in a Ran-unassisted manner. Mol. Biol. Cell 10: 1119-1131.

Yoshida, Y., Tanaka, S., Umemori, H., Minowa, O., Usui, M., Ikematsu, N., Hosoda, E., Imamura, T., Kuno, J., Yamashita, T., et al. 2000. Negative regulation of $\mathrm{BMP} / \mathrm{Smad}$ signaling by Tob in osteoblasts. Cell 103: 1085-1097.

Yoshida, Y., von Bubnoff, A., Ikematsu, N., Blitz, I.L., Tsuzuku, J.K., Yoshida, E.H., Umemori, H., Miyazono, K., Yamamoto, T., and Cho, K.W. 2003. Tob proteins enhance inhibitory Smad-receptor interactions to repress BMP signaling. Mech. Dev. 120: 629-637.

Zavadil, J., Bitzer, M., Liang, D., Yang, Y.C., Massimi, A., Kneitz, S., Piek, E., and Bottinger, E.P. 2001. Genetic programs of epithelial cell plasticity directed by transforming growth factor- $\beta$. Proc. Natl. Acad. Sci. 98: 6686-6691.

Zawel, L., Dai, J.L., Buckhaults, P., Zhou, S., Kinzler, K.W., Vogelstein, B., and Kern, S.E. 1998. Human Smad3 and Smad4 are sequence-specific transcription activators. Mol. Cell 1: 611-617.

Zhang, Y. and Derynck, R. 2000. Transcriptional regulation of the transforming growth factor- $\beta$-inducible mouse germ line Ig $\alpha$ constant region gene by functional cooperation of Smad, CREB, and AML family members. J. Biol. Chem. 275: 1697916985.

Zhang, Y., Feng, X., We, R., and Derynck, R. 1996. Receptorassociated Mad homologues synergize as effectors of the TGF- $\beta$ response. Nature 383: $168-172$.

Zhang, Y., Feng, X.H., and Derynck, R. 1998. Smad3 and Smad4 cooperate with c-Jun/c-Fos to mediate TGF- $\beta$-induced transcription. Nature 394: 909-913.

Zhu, H., Kavsak, P., Abdollah, S., Wrana, J.L., and Thomsen, G.H. 1999. A SMAD ubiquitin ligase targets the BMP pathway and affects embryonic pattern formation. Nature 400: 687-693. 


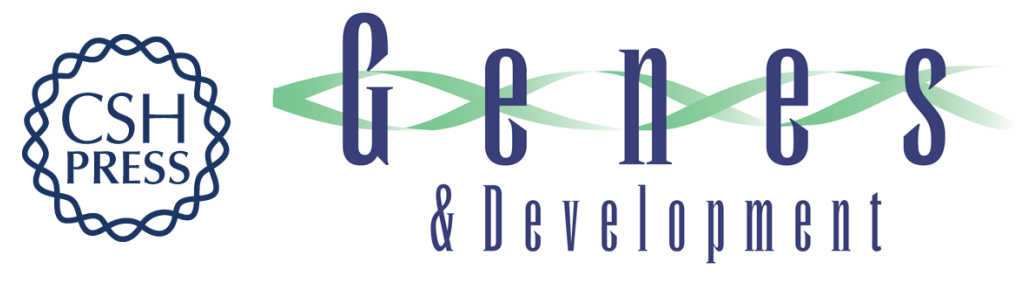

\section{Smad transcription factors}

Joan Massagué, Joan Seoane and David Wotton

Genes Dev. 2005, 19:

Access the most recent version at doi:10.1101/gad.1350705

References This article cites 255 articles, 138 of which can be accessed free at: http://genesdev.cshlp.org/content/19/23/2783.full.html\#ref-list-1

License

Email Alerting Receive free email alerts when new articles cite this article - sign up in the box at the top Service right corner of the article or click here.

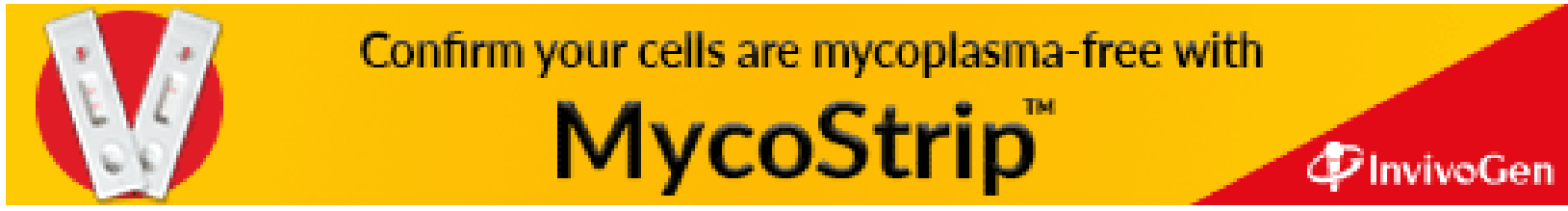

